\title{
STAATSHAFTUNG FÜR UNERLAUBTE HANDLUNGEN DER POLIZEIBEAMTEN IN DEUTSCHLAND MIT RECHTSVERGLEICHENDEN ANMERKUNGEN ZUM POLNISCHEN RECHT
}

\begin{abstract}
Zusammenfassung
Dervorliegende BeitragbefasstsichmitderAusgestaltungderhaftungsrechtlichen Verantwortung des Staates für unerlaubte Handlungen von Polizeibeamten in Deutschland. Schwerpunktmäßig wird auf die jeweiligen Tatbestandsvoraussetzungen des zentralen Amtshaftungsanspruchs (\$ 839 $B G B$ ) eingegangen. Es wird der Versuch unternommen, die zuweilen unübersichtliche Kasuistik anhand von strukturellen Erwägungen zu ordnen und damit dem Leser auch den Wirkungskreis der jeweiligen Tatbestandsmerkmale im Einzelnen sowie der Anspruchsnorm im Ganzen aufzuzeigen. Ferner werden nicht abschließend weitere bundes- und landesrechtliche Haftungsnormen behandelt und Regressansprüche des Staates gegenüber seinen Polizeibediensteten untersucht. Letztlich werden die Forschungsergebnisse in einer rechtsvergleichenden Schlussbetrachtung den polnischen Regelungen gegenübergestellt.
\end{abstract}

Schlüsselwörter

Staatshaftung - Amtshaftung - Kompensation - Polizei - unerlaubte Handlungen - polizeiliches Unrecht - Regress

\section{EINLEITUNG}

Die haftungsrechtliche Verantwortung des Staates wird in einem modernen Rechtsstaat als selbstverständlich angesehen. Nicht zuletzt deshalb, weilschadenstiftendeEreignisse sichniemals gänzlich ausschließen lassen. Die Gefahr der Beeinträchtigung von Rechten und Rechtsgütern steigt dabei deutlich im Falle einer kompetenzrechtlichen Asymmetrie. Diese ergibt sich regelmäßig aus staatlichen Prärogativen, die ihrerseits zwingend zu einem Überordnungsverhältnis des Staates gegenüber seinen

\footnotetext{
Der Verfasser ist wissenschaftlicher Mitarbeiter am Lehrstuhl für polnisches und europäisches Privatrecht sowie Rechtsvergleichung an der Europa-Universität Viadrina in Frankfurt an der Oder.
} 
Bürgern führen. Die Ausübung der hoheitlichen Gewalt gehört hierbei zweifelsfrei zu den originären Staatsaufgaben, die als solche auch für das friedlicheund geordneteZusammenlebenjeder menschlichen Gemeinschaft unabdingbar sind. Ein maßgeblicher Anteil an der Gewährleistung der Sicherheit und Durchsetzung des staatlichen Machtmonopols obliegt dem Pflichtenkreis der Polizei. Die sich aus der Natur der Sache ergebende unmittelbare Einwirkung auf Rechtspositionen Dritter, sei es bei präventiver Gefahrenabwehr oder repressiver Strafverfolgung, birgt als dessen Kehrseite das Risiko eines Schadenseintritts. In einem solchen Fall haben entsprechende rechtsstaatliche Haftungsinstitute die Funktion finanzielle Einbußen zu kompensieren und nichtvermögensrechtliche Schäden wiedergutzumachen.

Der vorliegende Beitrag befasst sich primär mit der Ausgestaltung der Staatshaftung für deliktisches, rechtswidriges Handeln der Polizeibeamten in Deutschland. Um das Verständnis der aktuellen Anspruchsgrundlagen zu erleichtern, erscheint es zweckmäßig in gebotener Kürze die Entwicklungsgeschichte des Haftungsinstituts nachzuzeichnen. Das dogmatisch verzwickte und teils wirre Regelungsgeflecht wird ohne das notwendige Hintergrundwissen kaum zu durchdringen sein. Entsprechend werden insbesondere die den heutigen Regelungen zugrundeliegenden Haftungsmodelle angesprochen. Die Ausgestaltung der Amtshaftung bestimmt hierbei den Schwerpunkt der Untersuchung. Die in § 839 BGB $^{1}$ i.V.m. Art. $39 \mathrm{GG}^{2}$ verankerte Anspruchsnorm stellt die wichtigste Säule der Staatshaftung dar und nimmt in der Rechtspraxis eine vorherrschende Stellung ein ${ }^{3}$. Gleichwohl können zahlreiche Entscheidungskriterien und Tatbestandsmerkmale in den geschriebenen Paragraphen nicht gefunden werden. Hinzu kommt, dass die teilweise durch die Rechtsprechung entwickelten Tatbestandsmerkmale und Haftungsbegrenzungen regelmäßig weich formuliert sind und hinreichende Orientierung für die Entscheidung eines Falles nur vermitteln, wenn man sie vor dem Hintergrund der einschlägigen Entscheidungen betrachtet ${ }^{4}$. Aus obigen Gründen werden auch $\mathrm{zu}$ rechtsvergleichenden Zwecken neben den Literaturmeinungen wichtige Entscheidungen aus der höchstrichterlichen

Bürgerliches Gesetzbuch in der Fassung der Bekanntmachung vom 2.01.2002 (BGBl. I S. 42, 2909; 2003 I S. 738), das zuletzt durch Artikel 16 des Gesetzes vom 29.06.2015 (BGBl. I S. 1042) geändert worden ist.

2 Grundgesetz für die Bundesrepublik Deutschland in der im Bundesgesetzblatt Teil III, Gliederungsnummer 100-1, veröffentlichten bereinigten Fassung, das zuletzt durch Artikel 1 des Gesetzes vom 23.12.2014 (BGBl. I S. 2438) geändert worden ist.

3 Vgl. F.J. Peine, Allgemeines Verwaltungsrecht, Heidelberg 2011, S. 268.

4 F. Ossenbühl, M. Cornils, Staatshaftungsrecht, München 2013, S. 5-6. 
Rechtsprechung anhand der jeweiligen Tatbestandsmerkmale eingehend behandelt. Im weiteren Verlauf des Beitrags wird ergänzend eine Auswahl von spezialgesetzlichen Haftungsnormen in Deutschland erörtert. Aufgrund der historischen und rechtsdogmatisch bedingten Eigenart der Staatshaftung verfügt die deutsche Rechtsordnung über eine Vielzahl an unterschiedlichen Haftungsinstituten, sodass es an einem geschlossenen Regelungssystem mangelt. Vor dem Hintergrund des Anliegens dieses Aufsatzes werden in diesem Abschnitt lediglich zwei besondere Tatbestände erläutert: die Unrechtshaftung der Polizei am Beispiel des brandenburgischen Ordnungsbehördengesetzes sowie das bundesrechtliche Strafverfolgungsentschädigungsgesetz.

Im Beitrag wird ebenfalls die Problematik des Rückgriffanspruchs des Staates gegen seine Polizeibediensteten beleuchtet. Hierbei wird zunächst die unmittelbare schadensrechtliche Verantwortlichkeit des schädigenden Polizeibeamten gegenüber dem Geschädigten thematisiert. Nachfolgend befasse ich mich ausführlich mit der Ausgestaltung des Innenverhältnisses zwischen dem Staat und seinen Polizeibeamten sowie den damit verbundenen Begrenzungen des Rückgriffrechts des Staates.

Abschließend wird unter Berücksichtigung der einschlägigen polnischen Regelungen und Rechtsprechung die Wirkungsweise der Staatshaftung beurteilt sowie der Versuch unternommen, etwaige strukturelle Unzulänglichkeiten zu identifizieren.

\section{HISTORISCHE ENTWICKLUNG DER DEUTSCHEN STAATSHAFTUNG}

\section{GRUNDSÄTZLICHES}

Die rechtliche Konstruktion des Amtshaftungsanspruches ${ }^{5}$ gemäß $\S 839$ BGB i.V.m. Art. 34 GG ist eng mit der deutschen Rechtsentwicklung verflochten. Sie weist Besonderheiten struktureller und inhaltlicher Art auf, die nur aus dem historischen Kontext, in dem diese Vorschrift steht, heraus verständlich sind ${ }^{6}$. In diesem Entwicklungsprozess sind alle

\footnotetext{
5 Der Amtshaftungsanspruch stellt eine besondere Ausprägung der haftungsrechtlichen Verantwortung des Staates dar. Der konstruktive und strukturelle Unterschied zwischen dem Amtshaftungsanspruch und dem Staatshaftungsanspruch im engeren Sinne rührt nach der h.M. von der unterschiedlichen Begründung des Anspruchs her: Bei der Staatshaftung handelt es sich um unmittelbare, bei der Amtshaftung um mittelbare, übernommene Haftung; dazu: H.J. Papier, [in:] F.J. Säcker, R. Rixecker (Hrsg.), Münchener Kommentar zum Bürgerlichen Gesetzbuch (MüKo), Band 5, München 2013, § 839 Rn. 8.

6 H.J. Papier, [in:] T. Maunz, G. Dürig, Grundgesetz-Kommentar, München 2015, Art. 34 Rn. 1.
} 
denkbaren Haftungsmodelle vorzufinden, darunter als die wichtigsten Ausprägungen die sog. Beamtenhaftung und die Verbandshaftung ${ }^{7}$. Im Rahmen der Beamtenhaftung haftet der jeweilige Beamte als Privatperson für unerlaubte Handlungen, die er in Ausübung seines Amtes einem Bürger zufügt. Im Falle der Verbandshaftung haftet für unerlaubte Handlungen des Beamten ausschließlich der Staat ${ }^{8}$.

\section{RECHTSGESCHICHTLICHE BEDEUTUNG UND INHALT DER BEAMTENHAFTUNG}

Die persönliche Haftung des Beamten gemäß § 839 BGB beruht auf der Rechtsvorstellung über das Staatsdienertum des ausgehenden 18. Jahrhunderts. Der Staat konnte nach damaliger Ansicht privatrechtliche Beziehungen mit seinen Bürgern eingehen und insoweit wie ein Privater haftbar gemacht und verklagt werden. Gleichzeitig galt der im Herrscher personifizierte hoheitlich handelnde Staat lange Zeit als unrechtsunfähig und damit grundsätzlich nicht haftbar'. Wegen dieser Fiktion bejahte das am 1.1.1900 in Kraft getretene Bürgerliche Gesetzbuch lediglich eine Haftung des Staates bei privatrechtlichem Handeln. Sie fand ihren gesetzlichen Niederschlag in § 31 BGB i.V.m. § 89 BGB. In Fällen, in denen der Staat hoheitlich tätig geworden ist, konnten gemäß § 839 BGB etwaige Haftungsansprüche nur gegen den handelnden Beamten gerichtet werden. Rechtshistorisch ist diese Konstruktion damit zu erklären, dass bereits im römischen Recht das Verhältnis zwischen Landesherrn und dessen Staatsdiener als privatrechtliches Mandatsverhältnis gedeutet wurde ${ }^{10}$. Handelte der Beamte rechtswidrig, so erfolgte die Handlung contra mandatum. Der pflichtwidrig handelnde Beamte überschritt demgemäß seine Vollmachten und konnte deshalb den Staat nicht verpflichten ${ }^{11}$. Die deliktische Eigenhaftung des Beamten nach dem für jedermann geltenden privaten Haftungsrecht war die notwendige Konsequenz.

Dieses Haftungsmodell fand Eingang in das neu geschaffene BGB, obwohl sich bereits zu Ende des 19. Jahrhunderts die Auffassung von einem öffentlich-rechtlichen Beamtenverhältnis durchsetzte ${ }^{12}$. Trotz massiver rechtspolitischer Forderung nach Einführung einer allgemeinen

Ossenbühl, Cornils, Fußnote 4, S. 8.

Peine, Fußnote 3, S. 269.

BVerfGE 61, 178.

10 H. Zoepfl, Grundsätze des gemeinen deutschen Staatsrechts, Zweiter Theil, Leipzig und Heidelberg 1863, S. 803.

11 Papier, [in:] MüKo, Fußnote 5, § 839 Rn. 5.

12 J. Kohl, Die Lehre von der Unrechtsfähigkeit des Staates, Köln 1977, S. 78 ff. 
Haftung des Staates im hoheitlichen Bereich, hat sich der Reichsgesetzgeber lediglich dazu entschlossen, die persönliche Haftung des Beamten gemäß $\S 839$ BGB zu normieren. Die staatliche Unrechtshaftung wurde demnach rechtssystematisch nicht nur formal in das Deliktsrecht aufgenommen, sondern in direkter Anlehnung an frühere Vorstellungen als materiell-privatrechtliche Beziehung verstanden ${ }^{13}$.

\section{EVOLUTION DES BEAMTENHAFTUNGSMODELLS}

\subsection{Länder und Deutsches Reich}

Die Ansicht, dass die Einstandspflicht des Staates für das Fehlverhalten seiner hoheitlich tätigen Beamten notwendig sei, setzte sich im Verlauf der Zeit jedoch auch in der Staatspraxis durch. Die meisten Einzelstaaten führten für ihre Landesbeamten entsprechende Regelungen ein. Diese sahen überwiegend vor, dass die nach § 839 I BGB gegen die Beamten gerichteten Forderungen auf den Staat übergingen. Es handelte sich demnach um eine Konstruktion der schuldbefreienden Haftungsübernahme ${ }^{14}$. Als Beispiel kann hier die preußische Vorschrift aus § 1 I des Gesetzes über die Haftung des Staates und anderer Verbände für Amtspflichtverletzungen von Beamten in Ausübung der öffentlichen Gewalt vom 1. August 1909 dienen. Eine ähnliche Regelung wurde ebenfalls vom Reichsgesetzgeber in Bezug auf Reichsbeamte gemäß $§ 1$ I des Gesetzes über die Haftung des Reichs für seine Beamten vom 22. Mai 1910 beschlossen.

Ferner ist festzuhalten, dass § 839 BGB inhaltlich lediglich die Wirkung einer Haftungsuntergrenze aufwies. Mehrere Landesgesetze haben den durch das BGB vorgegebenen Haftungsmaßstab inhaltlich bewusst erweitert und eine Verantwortlichkeit des Staates auch dann eintreten lassen, wenn kein Verschulden seitens des Beamten vorlag. Diese von der persönlichen Haftung des Beamten völlig losgelöste unmittelbare Staatshaftung fand ihren Widerhall in Art. 61 I des bayerischen ABGBG vom 9. Juni 1901. Es sind ebenfalls Regelungen in Form der beschränkten Billigkeitshaftung eingeführt worden (§ 1 III des Gesetzes für das Großherzogtum Oldenburg, betreffend der Haftung des Staates und anderer Verbände für Amtspflichtverletzungen der öffentlichen Gewalt vom 22. Dezember $1908)^{15}$.

\footnotetext{
13 BVerfGE 61, 179.

14 H. Gehre, Die Entwicklung der Amtshaftung in Deutschland seit dem 19. Jahrhundert, Bonn 1958, S. $102 \mathrm{ff}$.

15 H. Becher, Die gesamten Materialien zu dem Ausführungsgesetze zum Bürgerlichen Gesetzbuch vom 9. Juni 1899, Band 1, München 1901, S. 877 ff.
} 


\subsection{Weimarer Reichsverfassung}

Als Meilenstein in der Entwicklung des deutschen Staatshaftungsrechts erwies sich die im Jahre 1919 in Kraft getretene Weimarer Reichsverfassung $(\mathrm{WRV})^{16}$. Diese enthielt mit Art. 131 WRV eine Bestimmung, die nunmehr eine mittelbare Staatshaftung kraft befreiender normativer Haftungsübernahme vorsah. Anstelle der vorherigen Beamteneigenhaftung wurde nunmehr reichseinheitlich die Verantwortlichkeit des Beamten auf den Staat übergeleitet ${ }^{17}$. Der Art. 131 WRV lautete:

„Verletzt ein Beamter in Ausübung der ihm anvertrauten öffentlichen Gewalt die ihm einem Dritten gegenüber obliegende Amtspflicht, so trifft die Verantwortlichkeit grundsätzlich den Staat oder die Körperschaft, in deren Dienste der Beamte steht. Der Rückgriff gegen den Beamten bleibt vorbehalten. Der ordentliche Rechtsweg darf nicht ausgeschlossen werden.

Die nähere Regelung liegt der zuständigen Gesetzgebung ob“.

Durch diese Vorschrift wurde von Verfassungswegen für alle Amtsträger des Reiches, der Länder, der Kommunen sowie sonstiger juristischer Personen des öffentlichen Rechts des Reichs und der Länder die in § 839 BGB begründete Verantwortlichkeit vom schuldhaft handelnden Amtsträger auf die öffentliche Körperschaft übertragen ${ }^{18}$. Sie galt für den hoheitsrechtlichen Sektor der Staatsfunktionen und wies zugleich deutliche konstruktive, zum Teil aber auch inhaltliche Unterschiede im Verhältnis zur unmittelbaren, privatrechtlichen Organhaftung des Staates gemäß § 31 i.V.m. § 89 BGB auf. Auch Art. 131 WRV fußt auf der an die Mandatstheorie anknüpfenden Negierung einer unmittelbaren und eigenen Verantwortung des Staates. Die zivilrechtliche Verantwortlichkeit des Beamten wurde beibehalten, die nunmehr jedoch verfassungsbedingt auf den Staat übergeleitet wurde ${ }^{19}$. Der materiell-rechtliche Gehalt des Art. 131 WRV beschränkte sich auf einen Schuldnerwechsel, der gegenüber

\footnotetext{
$\overline{16}$ Die Verfassung des Deutschen Reichs (Weimarer Verfassung) vom 11.08.1919 (RGB1. S. 1383) mit späteren Änderungen.

17 Papier, [in:] Maunz, Dürig, Fußnote 6, Art. 34 Rn. 10.

18 P. Dagtoglou, [in:] W. Kahl, C. Waldhoff, C. Walter (Hrsg.), Bonner Kommentar zum Grundgesetz (BoKo), Heidelberg 2014, Art. 34 Rn. 20-22.

19 S. Pfab, Staatshaftung in Deutschland, München 1997, S. 14.
} 
dem jeweiligen Beamten der Wirkung einer befreienden Schuldübernahme gleichkam ${ }^{20}$. Diese Verfassungsregelung hat der Grundgesetzgeber in Art. 34 GG mit wenigen sprachlichen Änderungen übernommen ${ }^{21}$.

\section{DIE NORMSTRUKTUR UND DER NORMZWECK DES AMTSHAFTUNGSANSPRUCHS}

Die Vorschrift des Art. 34 Satz 1 GG bildet zusammen mit der einschlägigen Regelung des einfachen Rechts in $\S 839$ BGB gemeinsam die unmittelbar verbindliche Anspruchsgrundlage für Staatshaftungsansprüche ${ }^{22}$. Die obige Norm begründet dementsprechend eine objektiv-rechtliche Haftungsverpflichtung der staatlichen Gewalt, der ein gerichtlich durchsetzbarer Schadensersatzanspruch des Einzelnen entspricht ${ }^{23}$.

Umstritten ist hingegen die Art und Weise des Zusammenwirkens dieser Regelungen.

Nach der h.M. wird der $\S 839$ BGB als anspruchsbegründende deliktische Norm qualifiziert, während Art. 34 GG als verfassungsrechtliche Zurechnungsnorm den Anspruch vom Amtsträger auf denStaat überleitet ${ }^{24}$. Die in der Verfassung angesprochene Verantwortlichkeit wird durch die Merkmale des § 839 BGB ausgefüllt und die damit begründete persönliche Haftung bei hoheitlichem Handeln verfassungskräftig schuldbefreiend vom Staat übernommen ${ }^{25}$. Art. 34 Satz 1 normiert ein subjektives Recht des von der Amtshandlung Betroffenen, stellt jedoch weder ein Grundrecht noch ein grundrechtsgleiches Recht $\mathrm{dar}^{26}$. Die verfassungsrechtliche Norm enthält eine Institutsgarantie der Staatshaftung, welche eine Mindestgarantie der Haftung des Staates für die schuldhafte Verletzung von Rechtsvorschriften bestimmt ${ }^{27}$.

Demgegenüber versteht eine andere Meinung den Art. 34 Satz 1 GG als Ausfluss einer unmittelbaren Staatsverbandshaftung und somit als eigentliche Anspruchsgrundlage. § 839 BGB kommt nur eine

\footnotetext{
S. Detterbeck, K. Windthorst, H. Sproll, Staatshaftungsrecht, München 1999, S. 12.

Papier, [in:] Maunz/Dürig, Fußnote 6, Art. 34 Rn. 10.

Detterbeck, Windthorst/Sproll, Fußnote 20, § 3 Rn. 5.

Ibidem, § 8 Rn. 2.

BVerfG Neue Juristische Wochenschrift 1983, 25, 30; B. Grzeszik, [in:] V. Epping, C. Hillgruber (Hrsg.), Beck'scher Online-Kommentar-Grundgesetz, München 2015, Art. 34 Rn. 2.

25 Papier, [in:] MüKo, Fußnote 5, § 839 Rn. 117 ff.

26 K. Stern, Das Staatsrecht der Bundesrepublik Deutschland, Band III/1, München 1988, S. 1378.

27 H.J. Bonk, S. Detterbeck, [in:] M. Sachs (Hrsg.), Grundgesetz-Kommentar, München 2014, Art. 34 Rn. 3.
} 
konkretisierende Funktion zu. Als Begründung wird auf den offenen, vage formulierten Wortlaut des Art. 34 GG verwiesen ${ }^{28}$. Außerdem werden rechtsstaatliche Erwägungen angeführt, sodass Art. 34 GG als ranghöhere Norm gegenüber dem $\S 839$ BGB zu qualifizieren sei ${ }^{29}$.

Weiterhin wird eine vermittelnde Ansicht vertreten, die beide oben geäußerteMeinungen inhaltlichumfasst. DemnachisteineWechselwirkung zwischen der zivilrechtlichen Vorschrift und der Verfassungsnorm gegeben, wobei Art. 34 Satz 1 GG eine Doppelfunktion zugeschrieben wird. Einerseits wiederhole er die Tatbestandsmerkmale des § 839 BGB (z.B. Drittbezogenheit der verletzten Amtspflicht). Es spiegeln sich darin der Verfassungsauftrag und die Einrichtungsgarantie wider ${ }^{30}$. Andererseits modifiziert Art. 34 GG gewisse Tatbestandsmerkmale der zivilrechtlichen Vorschrift aufgrund seines Vorrangs gegenüber formellem Bundesrecht ${ }^{31}$. Rechtsmethodisch erfolgt dies im Wege einer verfassungskonformen Auslegung. § 839 BGB wird von der Verfassungsnorm überlagert ${ }^{32}$.

Die dritte, vermittelnde Ansicht ist vorzugswürdig, da sie die von der ersten und zweiten Meinung vertretenen Ansätze vermengt und eine komplexe und konsequente Einordung der Wechselwirkung zwischen § 839 BGB und Art. 34 GG ermöglicht.

\section{DIE EINZELNEN TATBESTANDSMERKMALE DES AMTSHAFTUNGSANSPRUCHS}

\section{BEAMTENBEGRIFF}

\subsection{Grundsätzliches Verständnis des Beamtenbegriffs}

Zum richtigen Verständnis dieses ersten Tatbestandsmerkmals ist der Umstand maßgeblich, dass der Begriff des Beamten völlig von der Person des handelnden Amtswalters losgelöst ist. Zwar muss gemäß dem Wortlaut des $\S 839$ BGB ein Beamter die verletzende Handlung begangen haben. Der Begriff „Beamter“ in § 839 BGB wird gleichwohl durch die Formulierung

\footnotetext{
Detterbeck, Windthorst, Sproll, Fußnote 20, § 8 Rn. 3.

9 H.D. Jarass, [in:] H.D. Jarass, B. Pieroth, Grundgesetz für die Bundesrepublik Deutschland, Kommentar, München 2012, Art. 34 Rn. 1.

30 Papier, [in:] MüKo, Fußnote 5, § 839 Rn. 125 f.

31 H.J. Papier, [in:] J. Isensee, P. Kirchhof (Hrsg.), Handbuch des Staatsrechts der Bundesrepublik Deutschland, Band 6, Heidelberg 2009, § 157 Rn. 14.

32 Detterbeck, Windthorst, Sproll, Fußnote 20, § 8 Rn. 4.
} 
„jemand“ in Art. 34 GG erweitert ${ }^{33}$. Diese Erweiterung führt dazu, dass die Rechtsstellung des Handelnden für den Amtshaftungsanspruch ganz unbeachtlich ist. Entscheidend ist vielmehr die ausgeübte Tätigkeit, die Amtsausübung. Die Amtshaftung ist dementsprechend keineStatushaftung im Sinne der Beamtenhaftung, sondern eine Funktionshaftung. Das Verständnis des "öffentlichen Amtes“ ist damit für die Reichweite der Amtshaftung ausschlaggebend ${ }^{34}$. In diesem Zusammenhang ist auch von einem Beamten im haftungsrechtlichen Sinne die Rede. Damit können auch Personen, die nicht in einem beamtenrechtlichen Dienstund Treueverhältnis stehen, Beamte im haftungsrechtlichen Sinne sein. Voraussetzung hierfür ist lediglich, dass sie mit der Wahrnehmung einer öffentlichen Aufgabe betraut sind ${ }^{35}$. Es kommt allein auf die Rechtsnatur des Handelns im Verhältnis zum Bürger $a^{36}$.

Danach sind unproblematisch Amtswalter alle Personen, die in einem öffentlich-rechtlichen Dienstverhältnis stehen ${ }^{37}$. Zum Kernbereich hoheitlicher Verwaltung zählt insbesondere die Polizeigewalt, die deshalb nur von Beamten im staatsrechtlichen Sinne ausgeübt werden darf ${ }^{38}$. Als Beamte im staatsrechtlichen Sinne sind Polizisten immer auch Beamte im haftungsrechtlichen Sinne, soweit diese eine polizeiliche Aufgabe wahrnehmen ${ }^{39}$. Gemäß § 109 BbgLBG $^{40}$ handelt es sich bei Polizisten im (brandenburgischen) Vollzugsdienst um Beamte im öffentlich-rechtlichen Dienstverhältnis, sodass diese den Regelfall des haftungsrechtlichen Beamtenbegriffs erfüllen.

\subsection{Staatshaftung für private Verwaltungshilfe}

Erhebliche Schwierigkeiten bereiten aber die Fälle, in denen ein selbständiger Privatunternehmer aufgrund eines privatrechtlichen Vertrages zur Erfüllung einer öffentlich-rechtlichen Aufgabe herangezogen wird. Es stellt sich die Frage, unter welchen Voraussetzungen sich der Staat das Verhalten einer Privatperson zurechnen lassen muss. Die zu diesem

\footnotetext{
Papier, [in:] Maunz, Dürig, Fußnote 6, Art. 34 Rn. 105.

Ossenbühl, Cornils, Fußnote 4, S. 14.

B. Tremml, M. Karger, M. Luber, Der Amtshaftungsprozess, München 2013, S. 14.

Peine, Fußnote 3, § 17 Rn. 1091.

Ossenbühl, Cornils, Fußnote 4, S. 15-16.

Vgl. Art. 33 IV GG.

F. Rachor, [in:] H. Lisken, E. Denninger (Hrsg.), Handbuch des Polizeirechts, München 2012,

40 Beamtengesetz für das Land Brandenburg vom 3.04.2009 (GVBl.I/09, [Nr. 04], S. 26), zuletzt geändert durch Artikel 11 des Gesetzes vom 13.03.2012 (GVBl.I/12, [Nr. 16]).
} S. 1339. 
wichtigen Problemkreis von der Rechtsprechung entwickelten Grundsätze waren im Verlauf der Zeit einem deutlichen strukturellen Wandel unterworfen und korrespondieren insoweit mit dem sich verändernden Bild des Staates als Rechtssubjekt. Zur Veranschaulichung dieser praxisrelevanten Problemstellung kann folgendes Fallbeispiel dienen.

Die städtische Polizei hatte ein privates Abschleppunternehmen damit beauftragt, einen verkehrsunsicheren Pkw durch Abschleppen auf den Hof des Polizeipräsidiums aus dem Verkehr zu ziehen. Es handelte sich hier um einen privatrechtlichen Vertrag zwischen der Polizeibehörde und dem Unternehmen. Der Auftrag wurde unsachgemäß ausgeführt und hatte einen Schaden am Pkw verursacht. Die Polizei war bei der Abschleppmaßnahme nicht zugegen ${ }^{41}$.

\subsubsection{Privater als Werkzeug des Hoheitsträgers}

Ausgangspunkt und notwendige Bedingung für die Annahme einer Staatshaftung war die Einstufung eines Privaten (hier des Abschleppunternehmens) als einen "unselbständigen Verwaltungshelfer". Im Unterschied $\mathrm{zu}$ einem Beliehenen ${ }^{42}$ übt der Private selbständig gerade keine hoheitlichen Kompetenzen aus ${ }^{43}$, sodass dieser nicht dem Beamtenbegriff des $\S 839$ BGB unterfällt. Eine taugliche Verknüpfung zwischen dem Verhalten des Hoheitsträgers (Polizei) und des Privaten (Unternehmen) ist anzunehmen, wenn die Anwendung der hoheitlichen Gewalt im Verhalten des Privaten weiter fortwirkt. Entsprechend müssten die maßgeblichen Entscheidungen von dem Hoheitsträger bereits getroffen sein und von dem Privaten lediglich "schematisch" ausgeführt werden $^{44}$. Dies ist im Regelfall nur dann gegeben, wenn der Private eine allein untergeordnete Hilfstätigkeit wahrnimmt und den Weisungen der Verwaltung weitgehend unterworfen ist. Gerade auf dieser Konstruktion baut die sog. Werkzeugtheorie auf, die den Privaten als Werkzeug der Verwaltung bei der Erfüllung hoheitlicher Aufgaben einstuft ${ }^{45}$. Fraglich ist,

\footnotetext{
$41 \quad$ Einen vergleichbaren Fall hatte das OLG Nürnberg zu entscheiden: Urteil vom 30.03.1966 - 4 U 133/65; Juristen Zeitung (JZ) 1967, 61.

$42 \mathrm{Zu}$ dieser Gruppe zählen u.a. der Bezirksschornsteinfeger (BGHZ 62, 372 = Neue Juristische Wochenschrift 1974, 1507, 1508) und die amtlich anerkannten Sachverständigen für den Kraftfahrzeugverkehr bei der Prüfung von Kraftfahrzeugen (BGHZ 49, 108, 111 = Neue Juristische Wochenschrift 1968, 443; BGH Neue Juristische Wochenschrift 1973, 458).

43 Vgl. Tremml, Karger, Luber, Fußnote 35, S. 16.

44 Vgl. etwa BGHZ 48, 98, 103 = Neue Juristische Wochenschrift 1967, 1857, 1858; siehe auch BGH Neue Juristische Wochenschrift 1971, 2220, 2221.

45 Vgl. BGHZ 48, 98, 103.
} 
ob in diesem Zusammenhang überhaupt von einer "Zurechnung" fremden Verschuldens gesprochen werden kann, und der Hoheitsträger in solchen Fällen vielmehr für sein eigenes, auf das tatsächliche Verhalten seines Gehilfen durchgreifendes Instruktionsverschulden haftet. Hinter der durch die Rechtsprechung entwickelten "Werkzeugtheorie“ steht jedenfalls der Gedanke, dass Verantwortlichkeit nur demjenigen zugeordnet werden kann, der das schädigende Geschehen in hinreichendem Maße beeinflussen kann.

Die Anwendung dieses Grundsatzes auf denobigenSachverhalt scheidet jedoch aus, da das durch die Polizei beauftragte Unternehmen die Aufgabe eigenständig und ohneÜberwachung durch den Hoheitsträger durchführt ${ }^{46}$. Somit kann das Abschleppunternehmen nicht als unselbständiger Verwaltungshelfer im Sinne der Werkzeugtheorie qualifiziert werden. Folglich fehlt dem Unternehmen die Amtsträgereigenschaft im Sinne von Art. 34 GG, sodass dem Geschädigten kein Amtshaftungsanspruch gegen das Abschleppunternehmen zusteht. Das Unternehmen bleibt für die Schadenszufügung beim Abschleppen dem Geschädigten nach § 823 BGB verantwortlich. Damit entfällt die nur subsidiäre Haftung der Polizei gemäß § 839 I Satz 2 BGB. Im Ergebnis haftet der Staat in seinem öffentlich-rechtlichen Funktionskreis nicht nach öffentlichem Recht, sondern allenfalls nach privatem Deliktsrecht gemäß § 831 BGB samt der Exkulpationsmöglichkeit ${ }^{47}$.

\subsubsection{Der öffentlich-rechtliche Funktionskreis}

DieBegrenzung der Verantwortlichkeit desStaates nur auf schädigendes Verhalten von unselbständigen Unternehmen wurde jedoch als unzureichend kritisiert $^{48}$ und letztlich von der höchstrichterlichen Rechtsprechung um ein weiteres Zurechnungskriterium ergänzt. Nach der Auffassung des $\mathrm{BGH}^{49}$ ist hierbei nicht mehr allein der Entscheidungsspielraum bzw. die Weisungsgebundenheit des Unternehmensentscheidend, sondernalshinreichenderAnknüpfungspunkt

\footnotetext{
46 Diese Unselbstständigkeit und „Werkzeug“-Eigenschaft wird man aber etwa bei den Schülerlotsen bejahen können; vgl. OLG Köln Neue Juristische Wochenschrift 1968, 655; U. Stelkens, Amtshaftung und Regress bei Schädigungen durch Verwaltungshelfer, Juristen Zeitung (JZ) 2004, 656; W. Martens, Übertragung von Hoheitsgewalt auf Schüler, Neue Juristische Wochenschrift 1970, 1029; M. Zuleeg, Beleihung mit Hoheitsgewalt, Verwaltungshilfe und privatrechtliches Handeln bei Schülern, Die Öffentliche Verwaltung (DÖV) 1970, 627.

47 Vgl. Papier, [in:] Maunz, Dürig, Fußnote 6, Art. 34 Rn. 113.

48 Vgl. etwa Papier, [in:] MüKo, Fußnote 5, § 839 Rn. 138.

49 BGHZ 121, 224.
} 
die Nähe zum öffentlich-rechtlichen Funktionsbereich geeignet. Als ergänzende Kriterien sieht der BGH den Charakter der wahrgenommenen Aufgabe, die Sachnähe der übertragenen Tätigkeit zu dieser Aufgabe sowie den Grad der Einbindung des Unternehmens in den behördlichen Pflichtenkreis an: "Je stärker der hoheitliche Charakter der Aufgabe in den Vordergrund tritt, je enger die Verbindung zwischen der übertragenen Tätigkeit und der Behörde zu erfüllenden hoheitlichen Aufgabe und je begrenzter der Entscheidungsspielraum des Unternehmens, desto näher liegt es, ihn als Beamten im haftungsrechtlichen Sinne anzusehen " ${ }^{50}$. Danach kann sich die öffentliche Gewalt jedenfalls im Bereich der polizeilichen Eingriffsverwaltung der Amtshaftung für fehlerhaftes Verhalten ihrer Bediensteten nicht dadurch entziehen, dass sie die Durchführung einer von ihr angeordneten Maßnahme durch privatrechtlichen Vertrag auf einen privaten Unternehmer überträgt ${ }^{51}$. Der Rechtsgedanke des § 278 BGB findet eine entsprechende Anwendung, wodurch das Unternehmen als „Erfüllungsgehilfe“ der öffentlichen Gewalt erscheint. Nach der Gesamtschau der obigen Kriterien wird die privatrechtlich vereinbarte Abschleppmaßnahme weiterhin als polizeiliche Vollstreckungsmaßnahme mit seinem hoheitlichen Charakter eigestuft ${ }^{52}$. Im Ergebnis wird das Abschleppunternehmen als „Erfüllungsgehilfe“ der Polizei gegenüber dem geschädigten Dritten tätig. Der Hoheitsträger bedient sich des Privaten zum eigenen Nutzen und kann und soll diesen deshalb auch kontrollieren ${ }^{53}$. Das Verschulden des Mitarbeiters des Abschleppunternehmens ist dem Staat damit zuzurechnen und eine Schadensersatzpflicht aufgrund der Amtshaftung ist gegeben.

Die Ausweitung der öffentlich-rechtlichen Amtshaftung auch auf Fälle der Einschaltung selbständiger Privater ist eine rechtspolitisch gerechtfertigte und rechtsdogmatisch vertretbare Entscheidung. Andernfalls würde es zu einem rechtssystematisch untragbaren Ergebnis kommen, wonach die interne Beziehung zum Hoheitsträger und nicht das nach außen manifestierte (hoheitliche) Handeln notwendige Bedingung für die Begründung der Amtshaftung wäre ${ }^{54}$.

\footnotetext{
BGHZ 121, 226.

Rachor, [in:] Lisken, Denninger, Fußnote 39, S. 1340.

Ossenbühl, Cornils, Fußnote 4, S. 25.

Insoweit ist die einschlägige Interessen- und Risikoabwägung wohl deckungsgleich mit dem Prinzip des respondeat superior bei privatrechtlichem Handeln; vgl. G. Wagner, [in:] R. Zimmermann (Hrsg.), Grundstrukturen des Europäischen Deliktsrechts, Baden-Baden 2003, S. 289.

54 Vgl. Papier, [in:] MüKo, Fußnote 5, § 839, Rn. 138.
} 


\section{HANDELN „IN AUSÜBUNG" EINES ÖFFENTLICHEN AMTES}

\subsection{Grundsätzliches}

Ein Amtshaftungsanspruch entsteht nur dann, wenn der Amtswalter "in Ausübung“ eines öffentlichen Amtes gehandelt hat. Ein Schadenersatzanspruch wird verneint, wenn der Schaden nur „bei Gelegenheit" der Amtsausübung entstanden ist. Dies ist dann anzunehmen, wenn ein Zurechnungszusammenhang zwischen dem Amt und der schädigenden Handlung nicht besteht ${ }^{55}$. Zwischen Amtsausübung und der Schadenszufügung muss also ein sachlicher und zeitlicher Zusammenhang bestehen, sodass die Handlung ebenfalls noch dem Bereich der hoheitlichen Betätigung zugerechnet werden $\mathrm{kann}^{56}$. Dies setzt kumulativ das Bestehen eines hinreichend engen äußeren und inneren Zusammenhangs voraus. Das erstgenannte Kriterium stellt auf den äußeren objektiven Geschehensablauf $\mathrm{ab}$, das letztgenannte auf die innere subjektive Motivationslage ${ }^{57}$. Dabei ist nicht auf die handelnde Person abzustellen, sondern auf die Funktion, deren Wahrnehmung die im konkreten Fall ausgeübte Tätigkeit dient ${ }^{58}$. Im Zweifel ist das Handeln eines Amtswalters dem Staat zuzurechnen ${ }^{59}$. Dies liegt in der besonderen Schutzbedürftigkeit des Bürgers begründet, sodass dementsprechend das Merkmal „in Ausübung“ weit auszulegen ist. Die praktische Dimension dieser extensiven Inhaltsbestimmung ist nicht nur in typischen Fallkonstellationen relevant. Gerade in gravierenden Fällen von Amtsmissbrauch unter Ausnutzung der dienstlichen Stellung von Organwaltern kann sich der Bürger die zuständigen Behörden und Bediensteten nicht selbst aussuchen ${ }^{60}$.

Das Tatbestandsmerkmal „in Ausübung“ wurde durch Judikate des BGH in zwei ähnlich gelagerten Fallkonstellationen entsprechend näher ausgeformt. Zwar besitzt der erste Fall keinen polizeilichen Anknüpfungspunkt. Aufgrund der Einzelumstände lässt sich jedoch der Tenor des ersten Urteils ohne Weiteres auf eine Auslegung des Merkmals „in Ausübung“ auf polizeiliche Sachverhalte ausweiten.

Papier, [in:] MüKo, Fußnote 5, § 839 Rn. 162 ff.

Ossenbühl, Cornils, Fußnote 4, S. 28.

Detterbeck, Windthorst, Sproll, Fußnote 20, S. 113.

W. Schlick, Die Rechtsprechung des BGH zu den öffentlich-rechtlichen Ersatzleistungen, Neue Juristische Wochenschrift 2008, 128.

59 J. Wieland, [in:] H. Dreier, Grundgesetz-Kommentar, Tübingen 2006, Art. 34 Rn. 43.

60 Vgl. Dagtouglou, [in:] BoKo, Fußnote 18, Art. 34 Rn. 100. 


\subsection{Die subjektive Motivationslage als begrenzendes Kriterium}

In dem ersten Urteil aus dem Jahr $1954^{61}$ hat der BGH den Begriff „der Ausübung " zunächsteng ausgelegt. Vorliegend hatteein Regimentsadjutant einen Truppenarzt fahrlässig erschossen. Die schädigende Handlung des im Dienst befindlichen Beamten wurde durch Rachegefühle ausgelöst. Der Regimentsadjutant wollte einen neben dem Arzt stehenden Leutnant anschießen, der die Befehle des Adjutanten nicht ordnungsgemäß ausgeführt hatte. Der Leutnant blieb unverletzt, der Arzt erlitt eine tödliche Schusswunde.

Der BGH hat im obigen Fall zwar einen äußeren Zusammenhang zwischen der schädigenden Handlung und dem Dienst des Soldaten bejaht. Als der den Schuss aus seiner Maschinenpistole abgab, hat sich der Soldat im Dienst befunden. Das Gericht verneinte jedoch den inneren Zusammenhang zwischen der schädigenden Handlung und dem Dienst. Schießt ein Beamter im Dienst mit der Dienstwaffe auf eine Person, um sich an ihr zu rächen, so wird der zwischen der schädigenden Handlung und dem Dienst des Beamten erforderliche innere Zusammenhang nicht hergestellt. Unbeachtlich sei, dass die Verärgerung des Beamten, die seine Rachegefühle hervorgerufen hatte, durch Vorkommnisse im Dienst veranlasst war. Es hat sich hierbei nämlich um eine nicht nachvollziehbare Überreaktion gehandelt, die strafrechtlich gegebenenfalls als Mord zu qualifizieren wäre. Im Ergebnis bestand zwischen der Motivationslage des Schädigers kein hinreichender Zusammenhang mit der durch die Aufgabenstellung vorgezeichneten Amtsausübung. Die Einstandspflicht des Staates entfällt, sodass nur der unmittelbare Schädiger haftbar gemacht werden kann.

\subsection{Unbeachtlichkeit der subjektiven Motivationslage bei einer hervorgehobenen Amtsstellung}

In einem späteren Urteil aus dem Jahr $2002^{62}$ hat der BGH den Begriff "der Ausübung" weiterentwickelt. Vorliegend hat eine Polizistin infolge wochenlanger psychischer Schikanen ihres Vorgesetzten Selbstmord begangen. Kläger war der Vater der Polizistin. Er verlangte Schmerzensgeld sowie Erstattung der Beerdigungskosten vom Freistaat Bayern als Dienstherrn des beklagten Polizisten. In einem Abschiedsbrief hatte die verstorbene Polizistin geäußert, sie habe keine Lust mehr, sich vom

61 BGH, Urteil vom 26.11.1953, III ZR 26/52.

62 BGH, Beschluss vom 1.08.2002, III ZR 277/01. 
Vorgesetzten quälen zu lassen. Der Kläger hat vorgetragen, der Beklagte habe seine Tochter fortlaufend herabgewürdigt und sie in obszöner Weise beleidigt. Der vom Beklagten ausgeübte Psychoterror sei Ausdruck seiner frauenfeindlichen Grundhaltung gewesen. Er habe seinen geradezu triebhaften Zwang, Frauen zu erniedrigen und zu demütigen, aus rein persönlichen Motiven im Dienst ausgelebt.

Der BGH hat entschieden, dass ein Vorgesetzter, der im Rahmen der gemeinsamen Dienstausübung einen Untergebenen respektlos behandelt, regelmäßig hoheitlich tätig ist. Die Zielsetzung der Funktion eines Vorgesetzten steht in einem unmittelbaren inneren und äußeren Zusammenhang mit der schädigenden Handlung. Dies hat zur Folge, dass für etwaige daraus entstehende Gesundheitsschäden des Untergebenen nach Amtshaftungsgrundsätzen nicht der vorgesetzte Beamte persönlich, sondern dessen Dienstherr haftet. Dem steht der Umstand nicht entgegen, dass jedenfalls bezüglich der fortgesetzten anstößigen Beleidigungen ein konkreter dienstlicher Anlass nicht immer erkennbar war (die Äußerungen waren nur als Ausdruck einer frauenfeindlichen Grundhaltung des Beklagten). Der Begriff der Ausübung eines öffentlichen Amtes sei nämlich weit auszulegen. So schließt auch ein Missbrauch des Amtes zu eigennützigen, schikanösen oder gar strafbaren Zwecken eine Pflichtwidrigkeit aus eigensüchtigen oder rein persönlichen Gründen den Zusammenhang zwischen Amtsausübung und schädigendem Verhalten nicht von vornherein aus. Darüber hinaus ist $\mathrm{zu}$ beachten, dass der gesamte Tätigkeitsbereich, der sich auf die Erfüllung einer bestimmten hoheitlichen Aufgabe bezieht, als Einheit betrachtet werden muss. Es ist nicht möglich die einheitliche Aufgabe in Einzelakte - teils hoheitlicher, teils bürgerlich-rechtlicher Art - aufzuspalten und einer gesonderten Beurteilung zu unterziehen. Hier hat der Beklagte seine hervorgehobene Amtsstellung im Einzelfall missbraucht. Die Schikanen, die während der Dienstzeiten stattgefunden haben, besitzen dementsprechend eindeutig einen dienstlichen Bezug und aktualisieren im Ergebnis die Amtshaftung gem. Art. 34 GG i.V.m. § 839 BGB. 


\section{VERLETZUNG DER AMTSPFLICHT}

\subsection{Grundsätzliches}

Der Amtshaftungsanspruch aus Art. 34 GG i.V.m. § 839 BGB setzt weiterhin voraus, dass der Amtswalter eine Amtspflicht verletzt hat, die einem Dritten gegenüber bestand. Eine Legaldefinition bzw. ein Katalog von Amtspflichten, deren Verletzung die Amtshaftung aktualisiert, ist weder in Art. 34 GG noch in § 839 BGB vorzufinden. Der Tatbestand der Amtshaftung setzt die Definition der Amtspflicht vielmehr voraus und verweist damit auf andere Rechtsnormen ${ }^{63}$. Aufgrund der konstruktiven Besonderheit der Amtshaftung bestehen Amtspflichten ausschließlich im Verhältnis zwischen Amtswalter und Hoheitsträger (Dienstherrn). Zurechnungssubjekt dieser Pflichten bleibt jedoch der Amtswalter selbst ${ }^{64}$. Der Begriff der Amtspflicht knüpft dementsprechend an die persönliche Verhaltenspflicht des Beamten an.

Amtspflichten ergeben sich aus allen denkbaren Rechtsquellen wie dem Unionsrecht, der Verfassung, den Gesetzen, Rechtsverordnungen und Satzungen, dem Gewohnheitsrecht, allgemeinen Rechtsgrundsätzen sowie allgemeinen Dienst- und Verwaltungsvorschriften, Weisungen und Befehlen. Diese werden aber in ihrer konkreten Gestalt im Regelfall durch die Rechtsprechung ausgeformt. Der Amtsträger ist verpflichtet, sein Amt sachlich und unparteiisch auszuüben. Er ist verpflichtet, die geltenden Rechtsnormen zu befolgen sowie die Grundsätze von Treu und Glauben und guter Sitte anzuwenden ${ }^{65}$.

Besonders hervorzuheben ist, dass jeder Verstoß gegen Recht, das vom Staat beachtet werden muss, gleichzeitig einen Verstoß gegen Amtspflichten darstellt. Somit begründet jede Rechtspflichtverletzung im Außenverhältnis eine Amtspflichtverletzung im Innenverhältnis. Konstruktiv betrachtet, geschieht dies mittels der Amtspflicht zu rechtsmäßigem Verhalten der Verwaltung gemäß Art. 20 III GG. Die Unterschiede zwischen Rechtspflichten und Amtspflichten betreffen insoweit allein die konstruktive Begründung der Haftung, nicht aber ihren Erfolg. Damit wird die teilweise in der Lehre angenommene Divergenz von Amtspflichten und Rechtspflichten beseitigt ${ }^{66}$.

\footnotetext{
Papier, [in:] MüKo, Fußnote 5, § 839 Rn. 165.

64 D. Ehlert, [in:] H.G. Bamberger, H. Roth (Hrsg.), Beck'scher Online-Kommentar BGB, München 2015, § 839 Rn. 35.

65 Detterbeck, Windthorst, Sproll, Fußnote 20, S. 116.

66 Ibidem, S. 85.
} 
Das durch die fehlende einheitliche gesetzliche Festlegung der Amtspflichten bedingte "Vakuum" wurde durch die Rechtsprechung und Lehre ausgefüllt. Dies zieht nach sich, dass ein fester, abschließender Pflichtenkatalog nicht erkennbar ist. Gleichwohl ist eine gewisse Systematisierung der Amtspflichten im Hinblick auf polizeiliche Tätigkeiten möglich. Nachfolgend werden mittels richterlicher Entscheidungen die Ausprägungen der polizeilichen Amtspflicht zu rechtmäßigem Handeln konkretisiert. Hierbei handelt es sich um eine nicht abschließende Darstellung von Amtspflichten.

\subsection{Amtspflicht zu verhältnismäßigem Verhalten}

In einem Urteil des LG Baden-Baden ${ }^{67}$ wurde auf die Amtspflicht der Polizei zu verhältnismäßigem Verhalten näher eingegangen. Der Kläger stand im Verdacht, in alkoholbedingt fahruntüchtigem Zustand auf einem Parkplatz mit der Tür seines Pkw einen anderen geparkten Wagen beschädigt und anschließend Unfallflucht begangen zu haben. Die mit dem Fall befassten Polizeibeamten suchten den bei seinen Eltern wohnenden Kläger zu Hause auf, um ihn zur Entnahme einer Blutprobe vorläufig festzunehmen. Sie begaben sich dabei gegen den erklärten Willen der Eltern des Klägers und ohne Zuziehung neutraler Zeugen in das Zimmer des Klägers, fanden diesen dort im Bett liegend und hoben ihn, als er der entsprechenden Aufforderung nicht nachkam, mit einem Polizeigriff aus dem Bett. Sie fesselten ihm anschließend die Hände auf den Rücken und führten ihn, als er urinieren wollte, in gefesseltem Zustand auf die Toilette. Sie blieben dort anwesend, als der Kläger urinierte. Der Kläger musste mit auf dem Rücken gefesselten Händen im nahen Beisein der zwei Polizeibeamten urinieren, nachdem ihm seine Mutter - er selbst war hierzu wegen der Fesselung nicht in der Lage - die Hose geöffnet hatte.

Das Gericht stellte klar, dass jedes staatliche Handeln unter dem Gebot der Verhältnismäßigkeit und unter dem Verbot des Übermaßes steht. Dies ist insbesondere bei Eingriffen in grundrechtlich geschützte Bereiche wie die Intimsphäre der Fall. Vorliegend haben die diensttätigen Polizisten die Intimsphäre des Klägers widerrechtlich und schuldhaft schwer verletzt, indem sie den Kläger auch beim Aufsuchen der Toilette weder ganz noch teilweise von den Handschellen befreiten. Die Verletzung der Intimsphäre

67 LG Baden-Baden, Urteil vom 30.11.1990, 2 O 135/90. 
wäre nur dann gerechtfertigt gewesen, wenn dieser Eingriff geeignet und erforderlich für die Durchführung der vorläufigen Festnahme und den Abtransport des Klägers zur Polizeidienststelle gewesen wäre.

Im Streitfall war es nicht notwendig, den Kläger so zu fesseln, dass er nicht einmal ohne Hilfe anderer Personen urinieren konnte. Da der Kläger nicht im Verdacht einer schweren Straftat mit entsprechend gewichtigen Folgen stand, hätten ihm die Fesseln beim Besuch der Toilette abgenommen werden können. Die Polizisten verstießen im Ergebnis gegen das Verbot des Übermaßes. Sie verletzten damit die gegenüber dem Kläger bestehende Amtspflicht und handelten im Übrigen rechtswidrig und schuldhaft.

\subsection{Amtspflicht zur fehlerfreien Ermessensausübung}

Zunächst ist zu klären, inwieweit es sich bei den Entscheidungen der Polizei über die Voraussetzungen und die Durchführung ihrer Maßnahmen zur Gefahrenabwehr um Ermessens- und inwieweit um Rechtsfragen handelt. Grundsätzlich ist die Entscheidung darüber, ob eine Gefahr als Voraussetzung für ein polizeiliches Einschreiten besteht, nicht eine Ermessens-, sondern eine im Rechtsstreit voll nachprüfbare Rechtsfrage. Jedoch ist die Bestimmung des Umfangs der Untersuchung darüber, ob eine bestimmte Gefahr besteht, Ermessenssache der Polizei ${ }^{68}$. Die Amtspflicht zur fehlerfreien Ermessensausübung im Rahmen polizeilicher Tätigkeiten wurde im Urteil vom OLG Bremen ${ }^{69}$ näher bestimmt.

Vorliegend hat eine Gruppe von Jugendlichen am geparkten Pkw des Klägers manipuliert. Als der Kläger auf dem einschlägigen Parkplatz erschien, war die Polizei bereits mit mehreren Funkstreifenwagen eingetroffen. Bei dem Fahrzeug des Klägers war erfolglos versucht worden, mit einem Gegenstand die PKW-Tür zu öffnen. Die Polizeibeamten nahmen zwei Tatverdächtige vorläufig fest, um sie mit zum Polizeirevier nehmen zu können. Der Rest der Gruppe der Jugendlichen hielt sich weiter "in der Nähe" auf. Als die Polizeibeamten mit den beiden vorläufig festgenommenen Jugendlichen zum Polizeirevier fahren wollten, rief der Kläger den Polizeibeamten sinngemäß zu, sie möchten noch etwas warten und sie beide nicht allein lassen, da die Jugendlichen auf sie beide losgehen würden. Gleichwohl verließen die Polizeibeamten den Parkplatz und fuhren mit den beiden vorläufig festgenommenen Jugendlichen zum

\footnotetext{
68 G. Kreft, [in:] Das Bürgerliche Gesetzbuch mit besonderer Berücksichtigung der Rechtsprechung des Reichsgerichts und des Bundesgerichtshofs-Kommentar, herausgegeben von Mitgliedern des Bundesgerichtshofs (BGB-RGRK), Berlin 1980, § 839 Rn. 189.

69 OLG Bremen, Urteil vom 29.11.1989, 1 U 129/89.
} 
Polizeirevier. Nachdem der letzte Funkstreifenwagen fortgefahren war, schlugen die Jugendlichen kräftig auf den Kläger ein, der zu Boden ging. Kurz darauf traf die von der Ehefrau des Klägers benachrichtigte Polizei am Tatort ein und nahm die weiteren Ermittlungen auf. Der Kläger erlitt durch die Schläge der Jugendlichen schwere Gesichtsverletzungen.

Aufgrund des obigen Sachverhaltes wurde das beklagte Land nach Art. 34 S. 1 GG i.V.m. § 839 I BGB verpflichtet, dem Kläger ein angemessenes Schmerzensgeld zu zahlen. Die in ihrem Dienst stehenden Polizeibeamten haben fahrlässig eine ihnen dem Kläger gegenüber obliegende Amtspflicht verletzt und auf diese Weise bewirkt, dass der Kläger erhebliche körperliche Verletzungen erlitt. Nachdem die Polizeibeamten mit drei Streifenwagen angerückt waren und die von den Jugendlichen in Gang gesetzten Straftaten unterbunden hatten, bestand zumindest die hinreichende Wahrscheinlichkeit, dass die Jugendlichen sich an dem Kläger „rächen” würden, wenn die Beamten sie allein lassen würden. Es bestand zumindest eine erhebliche Gefahr für die körperliche Unversehrtheit des Klägers. Diese Gefahr war für die Beamten auch erkennbar, zumal sowohl der Kläger als auch seine Ehefrau die Beamten baten, sie nicht allein zu lassen. Sie äußerten die berechtigte Befürchtung, dass die Jugendlichen sofort auf sie beide losgehen würden.

Die Polizei hatte nach $\S 1$ I BremPG ${ }^{70}$ die Aufgabe, Gefahren für die öffentliche Sicherheit abzuwenden, wozu auch die Verhütung strafbarer Handlungen gehört, die dem Einzelnen drohen. Sie war folglich bei zutreffender Ausübung ihres pflichtgemäßen Ermessens verpflichtet, so lange zu warten, bis sich der Kläger und seine Ehefrau in Sicherheit gebracht hatten. Für eine Abwägung zwischen Zweck und Mittel blieb so gut wie kein Raum, da auf Seiten der Polizei, die mit drei Streifenwagen erschienen war, nur ein Zurückbleiben eines einzigen Wagens für wenige Minuten erforderlich gewesen wäre, während auf Seiten des Klägers eine erhebliche Körperschädigung drohte, die dann ja auch eingetreten ist. Die Polizei war umso mehr zum Warten verpflichtet, als gerade sie den Kläger und seine Ehefrau veranlasst hatte, den von den Jugendlichen aufgebrochenen Wagen zu sichern, also noch länger in Gegenwart der Jugendlichen auf dem Platz zu bleiben. Irgendeine Ermessensabwägung haben die Beamten ersichtlich gar nicht erst versucht, weil sie nur sinngemäß äußerten „daran könnten sie auch nichts machen".

Im Ergebnis ist festzustellen, dass die Polizei bei Vorliegen einer

70 Bremisches Polizeigesetz vom 6.12.2001 (Brem.GBl. S. 441, ber. 2002 S. 47), zuletzt geändert durch Art. 1 Gesetz zur vorübergehenden Unterbringung von Flüchtlingen und Asylbegehrenden vom 20.10.2015 (Brem.GBl. S. 464). 
Gefahr in der Regel einschreiten kann, nicht aber in jedem Fall einschreiten muss. Jedoch kann wie hier die Frage des polizeilichen Einschreitens das Ermessen auf "Null“ reduziert und daher ausgeschlossen sein. Die Polizei muss danach einschreiten, wenn es um die Abwendung einer unmittelbaren Gefahr für wesentliche Rechtsgüter wie die körperliche Integrität geht. Es besteht demnach ein Rechtsanspruch auf ein Einschreiten der Polizei, sofern ein Einschreiten möglich und erfolgsversprechend ist ${ }^{71}$.

\subsection{Amtspflicht zur Unterlassung unerlaubter Handlungen}

\subsubsection{Grundsätzliche Anwendbarkeit von Rechtfertigungsgründen}

Eine Klärung der Amtspflicht in Bezug auf unerlaubte Handlungen sowie des damit verbundenen Begriffs der Rechtswidrigkeit hat das OLG Celle $^{72}$ vorgenommen.

Dem einschlägigen Polizeieinsatz lag eine durch $S$ veranlasste Festnahme zugrunde. S führte zuvor in einem stark alkoholisierten Zustand einen Pkw. Die Polizeibeamten K und H, haben S gestellt. Sie forderten S, der zu diesem Zweck zunächst im Streifenwagen auf dem Rücksitz hinter dem Fahrer Platz genommen hatte, zu einem Atemalkoholtest auf. Als $S$ dies ablehnte, teilten die Beamten ihm mit, sie müssten ihn dann nach U. zur Dienststelle verbringen. Während der anschließenden Fahrt hat $S$ den vor ihm sitzenden Beamten $K$ mit einem Messer bedroht und verlangt, ihn zurück zu seinem Auto zu bringen. Diverse Schlichtungsversuche der Polizisten blieben erfolglos und mündeten schließlich in der Drohung eines Schusswaffengebrauchs. Als diese Maßnahme ebenfalls zu keinem Erfolg führte und S den Polizisten K weiterhin mit dem Messer bedrohte, schoss $\mathrm{H}$ auf den S. Durch den Schuss wurden innere Organe verletzt, wobei $S$ anschließend im Krankenhaus an einem Herz-Kreislaufversagen auf Grund der Schädigung der Bauch- und Brustorgane verstarb.

Den Polizeibeamten obliegt im Rahmen ihrer Amtspflicht zum gesetzmäßigen Verhalten auch die Pflicht, nach $\S \S 823$ ff. BGB tatbestandliche und rechtswidrige Eingriffe in die Rechte des Bürgers zu unterlassen. Ein nach allgemeinem Deliktsrecht rechtswidriger Eingriff gilt zugleich als eine Amtspflichtverletzung ${ }^{73}$. Jedoch hat hier der geschädigte $\mathrm{S}$, den Polizeibeamten K mit einem Messer bedroht, um ihn zur Umkehr

\footnotetext{
Vgl. BVerwGE 11, 97.

OLG Celle, Urteil vom 8.02.2000, 16 U 106/99.

Papier, [in:] MüKo, Fußnote 5, § 839 Rn. 196.
} 
und damit letztlich zum Unterlassen von Strafverfolgungsmaßnahmen zu veranlassen. Der Polizeibeamte hat diesen rechtswidrigen, gegenwärtigen Angriff von seinem Kollegen Sabgewehrt und damit in Notwehr gehandelt. Die Verletzung und letztlich Tötung des S war dementsprechend nach § 227 BGB (bzw. inhaltsgleich § $32 \mathrm{StGB}^{74}$ ) gerechtfertigt. Eine durch Notwehr bzw. Nothilfe gebotene Handlung schließt folglich die Widerrechtlichkeit der Amtspflichtverletzung aus ${ }^{75}$. Das Notwehrrecht steht trotz der Sonderregelungen in den Polizeigesetzen der Länder auch den Polizeibeamten $\mathrm{zu}^{76}$.

\subsubsection{Grenzen der Rechtfertigungsgründe}

In einem weiteren Fall hatte das OLG Frankfurt am Main ${ }^{77}$ ebenfalls $\mathrm{zu}$ beurteilen, ob eine pflichtwidrige unerlaubte Handlung von Polizisten begangen wurde. Im Rahmen dieses Beschlusses über Gewährung einer Prozesskostenhilfe in einer Amtshaftungsklage auf Schadensersatz musste das Gericht vorab über eine mögliche Verletzung von Amtspflichten gegenüber dem Antragssteller entscheiden. Das Gericht war dazu gehalten, gemäß § $114 \mathrm{ZPO}^{78}$ darüber zu bescheiden, ob die beabsichtigte Klage hinreichende Erfolgsaussichten bietet.

Vorliegend hat der Antragssteller vorgebracht, dass er Schäden in Zusammenhang mit seiner Festnahme und den polizeilichen Ermittlungen erlitten hatte. Es wurde ihm vorgeworfen den Sohn einer bekannten Familie mit dem Ziel entführt zu haben, Lösegeld zu erpressen. Der Antragssteller nahm Amtspflichtverletzungen der beteiligten Polizeibeamten unter mehreren Gesichtspunkten an. Zum einen sei er anlässlich der Festnahme durch ein Mobiles Einsatzkommando auf Grund massiver Gewaltanwendung verletzt worden. Weiterhin hat ein Polizeibeamter eine Folterdrohung ausgesprochen. Der Polizeibeamte hat behauptet, es sei angeordnet und in die Wege geleitet worden, ihm von einem Spezialisten, der bereits mit dem Hubschrauber unterwegs sei, Schmerzen zufügen zu lassen, damit er Einzelheiten zum Aufenthaltsort des Kindes nenne.

\footnotetext{
${ }_{74} \quad$ Strafgesetzbuch in der Fassung der Bekanntmachung vom 13.11.1998 (BGBl. IS. 3322), das zuletzt durch Artikel 14 Nummer 10 des Gesetzes vom 20.10.2015 (BGBl. I S. 1722) geändert worden ist.

75 Vgl. Ossenbühl, Cornils, Fußnote 4, S. 58 f.

76 J. Ellenberger, [in:] O. Palandt, Bürgerliches Gesetzbuch, München 2015, § 227 Rn. 3.

77 OLG Frankfurt/Main, Beschluss vom 28.02.2007, 1 W 47/06.

78 In der Fassung der Bekanntmachung vom 5.12.2005 (BGBl. I S. 3202, ber. 2006 I S. 431, 2007 I S. 1781) zuletzt geändert durch Verordnung vom 31.08.2015 (BGBl. I S. 1474) m.W.v. 8.09.2015.
} 
Diese Drohung habe nach Ansicht des Klägers gegen die Menschenwürde (Art. 1 I Satz 1 GG) und das Folterverbot des Grundgesetzes (Art. 104 I Satz 2 GG) und der Europäischen Menschenrechtskonvention (Art. 3 EMRK) verstoßen.

Das Gericht hat eine Amtspflichtverletzung der an der Festnahme beteiligten Polizeibeamten verneint. Zwar hat der Antragsteller einige Hautabschürfungen und weitere kleine Verletzungen erlitten. Diese Verletzungen lassen jedoch nicht den Rückschluss auf ein nicht verhältnismäßiges Vorgehen der Polizeibeamten bei der Festnahme zu. Immerhin stand der gravierende Vorwurf der Beteiligung an einem erpresserischen Menschenraub im Raum, sodass die festnehmenden Polizeibeamten nach erfolgter Aushändigung des Lösegelds mit einem nicht unerheblichen Potenzial an Gegenwehr bei einer Festnahme rechnen und darauf bedacht sein durften, einer derartigen Gegenwehr angemessen entgegenzuwirken.

Hingegen hat das Gericht eine Amtspflichtverletzung im Hinblick auf die ausgesprochene Folterdrohung angenommen. Hierbei folgte das Gericht der rechtlichen Bewertung des zuständigen Strafgerichts, dass zuvor über die Strafbarkeit des Polizeibeamten zu urteilen hatte. So sei das Verhalten des Polizisten als ein Verstoß gegen die grundrechtlich garantierte, als unantastbar qualifizierte Menschenwürde (Art. 1 I Satz 1 GG) und gegen das Verbot des Art. 104 I Satz 2 GG, festgehaltene Personen weder körperlich noch seelisch zu misshandeln, anzusehen. Dieses war nämlich weder durch eine polizeiliche Ermächtigungsklausel noch durch allgemeine strafrechtliche Rechtfertigungs- oder Entschuldigungsgründe gedeckt. Dies hat auch angesichts der Tatsache zu gelten, dass die Gewaltandrohung ganz eindeutig die als solche achtenswerte, zutiefst menschliche Zielrichtung hatte, Einzelheiten über den Aufenthaltsort des Kindes in Erfahrung zu bringen, um das Leben des Kindes möglicherweise retten zu können. Gleichwohl ist ein solches Verhalten grundsätzlich einer Abwägung unzugänglich. Dies ist auf den verfassungsrechtlich garantierten Schutz der Menschenwürde in seiner Absolutheit zurückzuführen. $\mathrm{Ob}$ eine Ausnahme als allerletztes Mittel in extremen Grenzfällen gemacht werden durfte, musste hier nicht entschieden werden. Es standen nämlich noch andere Mittel zur Verfügung, die nicht gänzlich ohne Aussicht auf Erfolg erschienen, um den Antragsteller zu Angaben über den Verbleib des Kindes zu bewegen. Das genannte Verhalten hat dem Antragsteller derart Angst gemacht, dass er schließlich doch zutreffend den Ort mitteilte, wo sich das 
Kind befand. Die zuvor durch das Strafgericht festgestellte Strafbarkeit des geschilderten Verhaltens als Nötigung gemäß § 240 StGB stellt im Ergebnis zugleich eine Amtspflichtverletzung gegenüber dem Antragsteller dar.

\subsection{Verletzung der Amtspflicht durch Unterlassen}

Die Verletzung der Amtspflicht besteht im amtspflichtwidrigen Verhalten des Amtsträgers. Dieses anspruchsbegründende Verhalten kann nicht nur, wie oben dargestellt, in einem rechtswidrigen Handeln, sondern auch in einem rechtswidrigen Unterlassen liegen. Dies setzt voraus, dass den Amtswalter eine entsprechende Pflicht zum Handeln trifft ${ }^{79}$.

Als Beispiel dient das Urteil des OLG Hamm ${ }^{80}$. Während eines Polizeieinsatzes, der zum Ziel hatte, eine fortdauernde Schlägerei zu unterbinden, kam einer der an der Schlägerei Beteiligten zu Schaden. Er wurde durch einen eingesetzten Polizeihund in den Kopf gebissen und erlitt hierdurch eine schwere Körperverletzung. Der Polizeibeamte hat den Diensthund nicht gezielt gegen den Geschädigten eingesetzt.

Dem zu Schaden gekommenen Kläger wurde ein Schadensersatz und Schmerzensgeld aufgrund eines amtspflichtwidrigen Verhaltens des Polizeibeamten gemäß § 839 BGB zugesprochen. Der Polizeibeamte hat den Diensthund im Rahmen hoheitlicher Tätigkeit eingesetzt. Es realisierte sich die typische Tiergefahr, da der Polizeihund spontan zugebissen hat, um einen tatsächlichen oder vermeintlichen Angriff des Klägers auf den Beamten abzuwehren. Obwohl diese Abwehrhandlung grundsätzlich als Nothilfe qualifiziert werden kann, verletzte der Polizeibeamte im konkreten Fall seine Amtspflichten. Das Gericht hat nämlich festgestellt, dass der Polizeibeamte die im Verkehr erforderliche Sorgfalt nicht beachtet hatte. Insbesondere warf das Gericht dem Polizeibeamten vor, dass der Polizeihund allenfalls bei einem tatsächlichen, nicht jedoch bei einem nur vermeintlichen Angriff zubeißen durfte. Denn nicht der Hund, sondern der Beamte als Hundeführer muss darüber entscheiden, ob in der konkreten Situation ein tatsächlicher Angriff vorliegt und ob der Hund ihn, den Beamten, durch Zubeißen schützen darf oder nicht. Der Beamte genügt der im Verkehr erforderlichen Sorgfalt nur dann, wenn er sicherstellt, dass er, der Beamte, die Situation beherrscht und nicht der Hund. Der Polizeibeamte hat eine Amtspflichtverletzung durch Unterlassen begangen.

Das Gericht hat in diesem Zusammenhang ebenfalls eine

79 Vgl. BGH NVwZ 1990, 699.

80 NVwZ - RR 1997, 460. 
Konkurrenzfrage zwischen zwei Anspruchsgrundlagen geklärt. Entsteht einem Dritten durch den Einsatz eines Polizeihundes ein Schaden und kommt als Haftungsnorm § 839 BGB in Betracht, dann verdrängt diese als Spezialvorschrift den § 833 BGB.

\section{DRITTBEZOGENHEIT DER AMTSPFLICHT}

Es reicht zur Begründung des Amtshaftungsanspruchs nicht aus, dass jemand durch die Amtspflichtverletzung nachteilig betroffen worden ist. Der Geschädigte muss vom Schutzbereich der Amtspflicht umfasst sein, d.h. er muss geltend machen können, dass die verletzte Amtspflicht gerade auch zu seinem Schutz diente. Den Gegensatz zu solchen Amtspflichten mit Drittbezogenheit bilden Amtspflichten, die allein die Aufrechterhaltung der öffentlichen Sicherheit und Ordnung bezwecken ${ }^{81}$. Die Drittgerichtetheit der Amtspflicht liegt entsprechend dann vor, wenn der verletzte Rechtssatz auch den Interessen des Geschädigten dienen soll. Dies ist bei den Vorschriften der Polizeigesetze durchweg der Fall. Sie dienen nicht nur dem öffentlichen Interesse an der Verhinderung von Schäden an Rechtsgütern. Als Ausprägung des Grundsatzes des Vorbehalts des Gesetzes dienen sie gleichzeitig den Interessen der Bürger. Sie bestimmen nämlich Umfang und Grenzen der Rechtsunterworfenheit des Bürgers und damit die Freiheitssphäre, die vorm staatlichen Zugriff geschützt ist ${ }^{82}$. Deshalb besitzt auch der das Polizeirecht prägende Verhältnismäßigkeitsgrundsatz drittschützenden Charakter. Darüber hinaus besteht gegenüber jedermann die Amtspflicht, unerlaubte Handlungen im Sinne des § 823 I BGB zu unterlassen. Es handelt sich hier um eine sog. "absolute“ Amtspflicht ${ }^{83}$. Die Pflicht zur ordnungsgemäßen Ermessenausübung dient wegen ihrer Ausrichtung am Zweck der Ermächtigung gemäß § $40 \mathrm{VwVfG}^{84}$ ebenfalls den Interessen des von einer Maßnahme Betroffenen und ist deshalb eine Amtspflicht, die dem Amtswalter einem Dritten gegenüber obliegt ${ }^{85}$.

\footnotetext{
Tremml, Karger, Luber, Fußnote 35, S. 26.

Rachor, [in:] Lisken, Denninger, Fußnote 39, S. 1342.

Vgl. Ossenbühl, Cornils, Fußnote 4, S. 61 f.

4 Verwaltungsverfahrensgesetz in der Fassung der Bekanntmachung vom 23.01.2003 (BGBl. I S. 102), das zuletzt durch Artikel 3 des Gesetzes vom 25.07.2013 (BGBl. I S. 2749) geändert

85 Vgl. Rachor, [in:] Lisken, Denninger, Fußnote 39, S. 1342.
} worden ist. 


\section{VERSCHULDEN}

\subsection{Grundsätzliches}

Das Erfordernis des Verschuldens ist zwar in Art. 34 GG nicht ausdrücklich erwähnt, findet aber in § 839 BGB seinen Ausdruck. Der Anspruch aus Amtspflichtverletzung setzt gemäß § 839 I BGB voraus, dass die Polizei ihre Rechtspflichten vorsätzlich oder fahrlässig verletzt. Die Amtshaftung greift deshalb nicht schon bei objektiver Pflichtwidrigkeit der Amtshandlung ein, sondern setzt eine schuldhafte Verletzung von Amtspflichten voraus.

$\mathrm{Ob}$ Vorsatz oder Fahrlässigkeit vorliegt, ist nicht für die Haftungsfrage an sich, sondern für etwaige Rückgriffansprüche gegen Beamte von Bedeutung. Vorsatz ist das Wissen und Wollen des rechtswidrigen Erfolgs. Er liegtauch dann vor, wenn der Amtswalter mindestens mitder Möglichkeit des Verstoßes gegen eine Amtspflicht rechnet und trotzdem handelt ${ }^{86}$. Nach § 276 I Satz 2 BGB handelt derjenige Beamte fahrlässig, der bei Beachtung der im Verkehr erforderlichen Sorgfalt die Amtspflichtverletzungen hätte voraussehen müssen ${ }^{87}$. Der Verschuldensmaßstab ist ein objektiver. Es ist nämlich nicht auf den konkret handelnden Amtswalter, sondern auf den „pflichtgetreuen Durchschnittsbeamten“ abzustellen ${ }^{88}$. Der Umstand, dass der handelnde Beamte die einschlägigen Vorschriften nicht kennt, führt nicht zum Haftungsausschluss. Die Beachtung der Gesetze und sonstiger Rechtsvorschriften bei der Ausübung hoheitlicher Gewalt ist Grundvoraussetzung für die Tätigkeit aller Amtsträger. Die Nichtkenntnis der für ein Tätigwerden einschlägigen Bestimmungen ist deshalb in aller Regel vorwerfbar. Es kommt auch nicht darauf an, ob sich die Unkenntnis auf elementare Normen oder auf Rechtsvorschriften von sekundärer Bedeutung bezieht ${ }^{89}$. Andernfalls würde derjenige Verwaltungsträger privilegiert, in dessen Dienst vorwiegend ignorante Amtswalter stehen. Nur in Fällen einer zweifelhaften Rechtslage ist eine Exkulpation des Amtswalters in Erwägung zu ziehen ${ }^{90}$.

\footnotetext{
Rachor, [in:] Lisken, Denninger, Fußnote 39, S. 1343.

H. Sprau, [in:] Palandt, Fußnote 77, § 839 Rn. 52.

H. Maurer, Allgemeines Verwaltungsrecht, München 2011, § 26 Rn. 24.

Rachor, [in:] Lisken, Denninger, Fußnote 39, S. 1343.

Ossenbühl, Cornils, Fußnote 4, S. 75.
} 
Ferner muss sich im Rahmen des $\S 839$ BGB das Verschulden immer auf die Verletzung der Amtspflicht beziehen. Es ist jedoch nicht erforderlich, dass der Beamte einen oder sogar den konkreten, aus der Pflichtverletzung entstehenden Schaden, voraussah oder voraussehen konnte ${ }^{91}$.

\subsection{Objektivierung des Verschuldens}

Grundsätzlich setzt die Haftung nach Art 34 GG i.V.m. § 839 BGB voraus, dass ein konkret feststellbarer Amtswalter eine ihm vorwerfbare Fehlleistung erbracht hat ${ }^{92}$. Hingegen tendiert die Rechtsprechung dazu, das Verschulden von der Person des konkret für den Schaden zuständigen Amtsträgers zu entkoppeln und stattdessen anhand objektiver Maßstäbe zu beurteilen ${ }^{93}$. Das Verschulden wird damit weitgehend

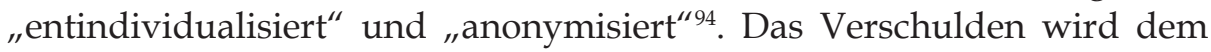
schlecht funktionierendem Verwaltungsapparat zugerechnet ${ }^{95}$. Dies erfolgt in erster Linie durch die Konstruktion des "Organisationsverschuldens". Für die Darlegungslast des Klägers im Amtshaftungsprozess bedeutet dies, dass er grundsätzlich den Amtsträger, der die schuldhafte Pflichtverletzung begangen hat, nicht namentlich benennen muss ${ }^{96}$. Dies ist besonders von Bedeutung, wenn der Bürger außerhalb der Verwaltungsorganisation der Behörde steht. Es ist dem Bürger nicht möglich und daher unzumutbar, die verantwortliche Person individuell zu bezeichnen ${ }^{97}$. Für die Aktualisierung des Amtshaftungsanspruchs reicht es demnach aus, dass ein Amtsträger Dritten gegenüber obliegende Amtspflichten verletzt hat. Es kommt also letztlich darauf an, dass das Gesamtverhalten der Verwaltung in einer den verkehrsnotwendigen Sorgfaltsanforderungen widersprechenden Weise amtspflichtwidrig war ${ }^{98}$.

Insoweit führt auch die Überforderung oder sogar Überlastung des einzelnen Polizeibeamten nicht zur Entlastung des Staates. Dies ist sogar dann der Fall, wenn der Grund hierfür in einer unzureichenden Ausbildung oder in vielen Überstunden des Polizisten liegt. Eine deshalb zur Regel gewordene und deshalb nicht mehr individuell vorwerfbare Überlastung ganzer Abteilungen oder Zweige der Vollzugspolizei ließe sich unter dem

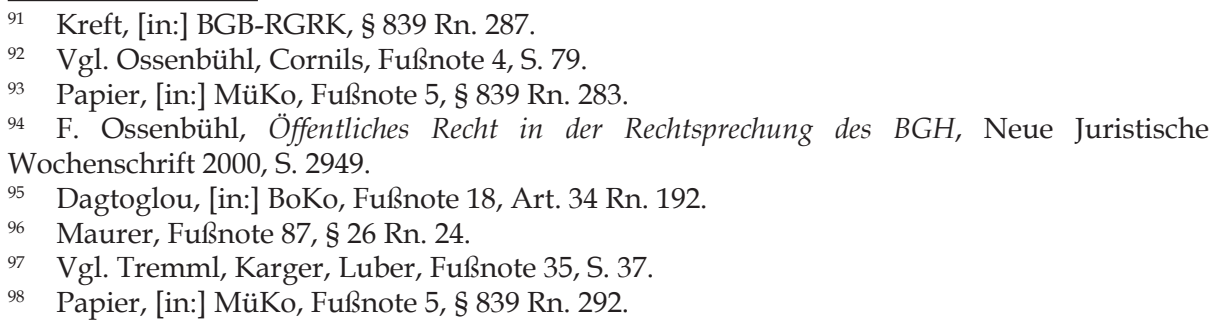


Gesichtspunkt des Organisationsverschuldens der Polizeiverwaltung als solcher zurechnen ${ }^{99}$. Schließlich ging die Rechtsprechung sogar dazu über, bezüglich des Verschuldens einen prima-facie-Beweis zuzulassen. Das Vorliegen einer Amtspflichtverletzung beinhaltet zugleich eine Schuldvermutung zu Lasten des betroffenen Amtswalters ${ }^{100}$.

Wann eine vorsätzliche Amtspflichtverletzung eines Beamten vorliegt, entschied der BGH in einem Urteil ${ }^{101}$ aus dem Jahr 1957. Zwei Polizeibeamte hielten sich während ihrer Dienstzeit in einer Unterkunft des Verkehrsdienstes auf und nutzten die Zeit zur Waffenpflege. Nach den Dienstvorschriften ist zum Laden und Entladen der Faustfeuerwaffen auf der Wache die Ladeecke - eine mit einem Sandkasten ausgestattete Ecke des dritten, hintersten Raumes der Unterkunft - zu benutzen. Einer der Polizisten (C) entlud seine Dienstwaffe entgegen den Dienstvorschriften nicht in der vorgeschriebenen Ladeecke. Dabei löste sich ein Schuss, der den Kläger schwer verwundete. Der Kläger ist seitdem dienstunfähig. Mit der Klage nimmt der Kläger die beklagte Stadt als Dienstherrin von C auf Schadensersatz in Anspruch. C wurde zuvor vom Strafgericht rechtskräftig wegen fahrlässiger Körperverletzung zu einer Geldstrafe verurteilt.

Das Gericht stelltefest, dass C während des Entladens seiner Dienstwaffe in Ausübung der ihm anvertrauten öffentlichen Gewalt gemäß Art. 34 GG handelte. Er hat ebenfalls eine Amtspflicht verletzt, da er entgegen den geltenden Dienstanweisungen seine Waffe nicht in der Ladeecke entlud. Hierbei wurde festgestellt, dass als Dritte im Sinne des Art. 34 GG i.V.m. $\S 839$ BGB auch andere Beamte qualifiziert werden können. Es sei keine notwendige Voraussetzung, dass sich beide dienstlich gleichgeordnet waren und nicht in einem hierarchischen Verhältnis zueinander standen. Aus dem Inhalt und Zweck der Dienstvorschrift ergibt sich nämlich, dass diese gerade auch den Schutz der Interessen aller derjenigen Personen bezweckt, die in den Gefahrenbereich der Schusswaffen kommen. Dazu gehören auch die Polizeibeamten, die sich während des Bereitschaftsdienstes oder der Wachzeit in der Polizeiunterkunft befinden.

Ferner hat das Gericht festgestellt, dass das Verschulden im Rahmen des $\S 839$ BGB sich stets auf die Verletzung der Amtspflicht beziehen muss. Ein vorsätzliches Handeln ist demnach gegeben, wenn der Beamte weiß, dass er pflichtwidrig handelt. Er muss sich mithin bewusst über die

99 Rachor, [in:] Lisken, Denninger, Fußnote 39, S. 1343.

100 H. Hinke, Zu den Bestimmungen über die Staatshaftung im Referentenentwurf eines Gesetzes zur Änderung und Ergänzung schadensrechtlicher Vorschriften, Deutsches Verwaltungsblatt (DVBl) 1967, 641.

101 BGH, Urteil vom 20.03.1961, III ZR 9/60 (Frankfurt). 
geltenden, seine Amtspflicht begründenden Bestimmungen hinwegsetzen oder zumindest mit der Möglichkeit eines Verstoßes gegen Amtspflichten rechnen und diese Pflichtverletzung in Kauf nehmen.

Dies hat das Gericht vorliegend angenommen, weil C unstreitig die verletzten Dienstvorschriften kannte. Es könne ihm nicht entgangen sein, dass der Kläger kurz vor dem Unfall seine Waffe in der Ladeecke entladen hatte, und weil er den Nebenraum mit der Ladeecke täglich vor Augen gehabt habe. $C$ habe sich demzufolge im Vertrauen darauf, dass nichts passieren werde, bewusst über die Vorschriften hinweggesetzt. Im Ergebnis stellte das Gericht eine vorsätzliche Amtspflichtverletzung des C fest.

\section{URSACHENZUSAMMENHANG}

\subsection{Grundsätzliches}

Die Schadensfolgen sind der Anstellungskörperschaft nur dann zuzurechnen, wenn sie durch das Verhalten des Amtswalters verursacht wurden. Der Schaden muss nicht auf der Beeinträchtigung eines geschützten Rechtsguts im Sinne von § 823 I BGB beruhen. Vielmehr werden nach § 839 BGB alle Vermögensschäden ersetzt, da es einen entsprechenden entschädigungsfähigen Rechtsgüterkatalog nicht gibt ${ }^{102}$. Inwieweit die Amtspflichtverletzung für den behaupteten Schaden ursächlich war, bemisst sich nicht nach der Äquivalenztheorie, sondern nach der Adäquanztheorie. Ein Amtspflichtverstoß ist deshalb nicht schon dann ursächlich für einen Schaden, wenn er eine notwendige Bedingung im logischen Sinne (conditio sine qua non) für den Schadenseintritt darstellt ${ }^{103}$. Vielmehr erfolgt die Zurechnung nur dann, wenn die vom handelnden Amtswalter gesetzte Bedingung im Allgemeinen zur Herbeiführung eines Erfolges geeignet war. Besonders eigenartige, ganz unwahrscheinliche und nach dem regelmäßigen Verlauf der Dinge atypische Umstände sind demnach außer Betracht zu lassen ${ }^{104}$.

102 Ossenbühl, Cornils, Fußnote 4, S. 73.

103 Rachor, [in:] Lisken, Denninger, Fußnote 39, S. 1343.

104 Vgl. W. Grunsky, [in:] MüKo, vor § 249 , Rn. 40. 


\subsection{Unterlassen}

Liegt die Verletzung der Amtspflicht hingegen in einem Unterlassen, so besteht ein Kausalzusammenhang zwischen Pflichtverletzung und Schaden nur dann, wenn das gebotene amtspflichtgemäße Handeln den Schadenseintritt mit an Sicherheit grenzender Wahrscheinlichkeit verhindert hätte. Eine bloße Möglichkeit oder Wahrscheinlichkeit genügt nicht ${ }^{105}$. Mit der Frage, ob ein Ursachenzusammenhang gegeben ist, hat sich der BGH im nachfolgenden Urteil befasst ${ }^{106}$.

Der Kläger erwarb einen gebrauchten $\mathrm{Pkw}$. Dieser wurde wegen mutmaßlicher Verfälschung der Motornummer von der Kriminalpolizei sichergestellt und verwahrt. Gegen den Fahrzeugverkäufer wurde ein strafrechtliches Ermittlungsverfahren eingeleitet. Anschließend drangen unbekannte Täter in die Halle ein und richteten an den dort abgestellten Fahrzeugen, darunter demjenigen des Klägers, erhebliche Schäden an. Der Kläger verlangte Ersatz der entstandenen Schäden.

Das Gericht lehnte einen Schadensersatzanspruch aus Amtspflichtverletzung ab. Aufgrund der Sicherstellung und Inverwahrungnahme des $\mathrm{Pkw}$ bestand die Amtspflicht, für die ordnungsgemäße Aufbewahrung des Fahrzeugs zu sorgen und die spätere unversehrte Rückgabe zu sichern. Die dazu im konkreten Fall gebotenen Sicherungsmaßnahmen wurden vorgenommen. Es lässt sich insbesondere kein Verstoß gegen Verfahrensvorschriften, Erfahrungssätze oder Denkgesetze erkennen.

Im Hinblick auf den Ursachenzusammenhang ist festzustellen, dass dieser in etwa den gleichen Voraussetzungen wie bei Ansprüchen aus Aufopferung unterliegt ${ }^{107}$. Im Sinne des Aufopferungsgedankens ist ein Verhalten für einen Schaden nach dem obigen Urteil dann kausal, wenn sich eine besondere Gefahr verwirklicht, die bereits in der hoheitlichen Maßnahme selbst angelegt ist, so dass sich der im konkreten Fall eintretende Nachteil aus der Eigenart der Maßnahme ergibt. Das ist hier nicht der Fall. Die Unterstellung eines sichergestellten und in Verwahrung genommenen Kraftfahrzeugs in der verschlossenen Halle eines Kraftfahrzeugbetriebes begründet nicht typischerweise die Gefahr, dass sich Dritte gewaltsam Zutritt verschaffen und das Fahrzeug vorsätzlich beschädigen. Wenn sich gleichwohl einmal ein solcher Schadensfall ereignet, so trifft dies den Eigentümer unabhängig davon, aus welchem Anlass sein Fahrzeug in der

105 Tremml, Karger, Luber, Fußnote 35, S. 39.

106 BGH, Urteil vom 09.04.1987, III ZR 3/86 (Celle).

107 Vgl. Rachor, [in:] Lisken, Denninger, Fußnote 39, S. 1343. 
Halle untergestellt ist. In einem solchen Fall verwirklicht sich eine Gefahr, die nicht schon in der Sicherstellung und Inverwahrungnahme selbst angelegt ist, also nicht aus deren Eigenart folgt. Vielmehr ist das Eigentum des Geschädigten dann durch ein außerhalb der hoheitlichen Maßnahme liegendes selbständiges Ereignis betroffen, das jederzeit auch zu anderer Gelegenheit hätte eintreten können. Es verwirklicht sich nur das allgemein zu tragende Risiko. Dass der Betroffene sein Fahrzeug möglicherweise besonders sorgfältig geschützt und damit schädigenden Einwirkungen Dritter entzogen hätte, ist angesichts der gebotenen typisierenden Betrachtungsweise unerheblich.

In einem bereits zuvor im Beitrag behandelten, früheren Urteil des $\mathrm{BGH}^{108}$ bezüglich der Verletzung eines Dienstkollegen mit einer Waffe wurde bereits ein ähnlicher Prüfungsansatz angewandt. Im Ergebnis hat das Gericht die Ursächlichkeit der Verletzung der Dienstvorschrift für den eingetretenen Schaden bejaht. Hierzu hat es eine Hypothese aufgestellt, wonach der Kläger von dem Schuss nicht getroffen worden wäre, hätte C seine Waffe in der Ladeecke ordnungsgemäß entladen. Demnach bauten die Dienstvorschriften gerade auf Erfahrungen aus früheren Unfällen beim Umgang mit Schusswaffen auf. Es liege deshalb nicht außerhalb der Lebenserfahrung, dass die Nichtbenutzung der Ladeecke einen Unfall dieser Art verursachen könne.

\section{SCHUTZZWECK DER NORM}

Die auf eine Wahrscheinlichkeitsprognose ausgerichtete Adäquanztheorie ist allein nicht ausreichend, die zurechenbaren Schadensfolgen zu begrenzen. Deshalb wird sie durch eine wertende Beurteilung ergänzt. Diese Beurteilung wird allgemein unter dem Kriterium des Schutzzwecks der Norm zusammengefasst ${ }^{109}$. Demnach ist ein Schaden nur dann ersatzfähig, wenn er in den Schutzbereich der verletzten Amtspflicht fällt. Die Amtspflicht muss gerade den Zweck haben, den Bürger von dem entsprechenden Nachteil zu schützen. Dieses Kriterium wird jedoch grundsätzlich bereits bei der Frage der Drittbezogenheit der Amtspflicht einschränkend eingesetzt ${ }^{110}$.

108 BGH, Urteil vom 20.03.1961, III ZR 9/60 (Frankfurt).

109 H. Heinrichs, [in:] Palandt, Fußnote 77, Vorb v § 249 Rn. 29.

110 Tremml, Karger, Luber, Fußnote 35, S. 40. 


\section{INHALT, ART UND UMFANG DES SCHADENSERSATZES}

\subsection{Inhalt und Art}

Für den Amtshaftungsanspruch gelten grundsätzlich die allgemeinen schadensrechtlichen Vorschriften der §§ 249 ff. und § 843 - § 846 BGB $^{111}$. Eine Besonderheit ist jedoch, dass alle Ersatzansprüche des Bürgers gegen den Staat ausschließlich auf Geldleistung gerichtet sein können. Der Amtshaftungsanspruch weicht insofern von der gesetzlichen Normallage des $\S 249 \mathrm{BGB}$ ab ${ }^{112}$. Dieser Kompensationsanspruch bezweckt lediglich den Ausgleich des erlittenen Schadens durch Geld ${ }^{113}$. Die Naturalrestitution ist wegen der Besonderheiten des Amtshaftungsrechts ausgeschlossen. Der Grund hierfür besteht in der Genese der Amtshaftungskonstruktion. Der Anspruch aus § 839 BGB begründet zunächst einen eigenständigen Anspruch gegen den Beamten. Dieser kann aber als Privatperson keine hoheitlichen Akte vornehmen, sondern nur Schadensersatz in Geld leisten. Gemäß Art. 34 GG wird die so umrissene Haftung des Beamten nur auf den Staat übergeleitet. Sie wird aber nicht erweitert, sodass im Ergebnis vom Staat nicht mehr verlangt werden kann als vom Beamten ${ }^{114}$. Ferner soll der Ausschluss einer Restitutionsmöglichkeit das Kompetenzgefüge der Rechtsprechungsorgane wahren. Es soll verhindert werden, dass die ordentlichen Gerichte durch die Verurteilung zur Vornahme einer hoheitlichen Tätigkeit in den Zuständigkeitsbereich der Verwaltungsgerichte eingreifen ${ }^{115}$. Begehrt der Geschädigte also Naturalrestitution, so kann er dies nicht mittels einer Amtshaftungsklage erreichen. Er ist hingegen gehalten einen öffentlich-rechtlichen Folgenbeseitigungsanspruch vor einem Verwaltungsgericht geltend $\mathrm{zu}$ machen ${ }^{116}$.

\subsection{Umfang}

Für die Berechnung des Umfangs des Schadensersatzes ist maßgeblich, wie sich die Vermögenslage des Betroffenen bei pflichtgemäßem Handeln des Amtsträgers entwickelt hätte. Der Schaden besteht demnach in

\footnotetext{
Sprau, [in:] Palandt, Fußnote 77, § 839 Rn. 78-79.

112 Papier, [in:] Maunz, Dürig, Fußnote 6, Art. 34 Rn. 233.

113 Rachor, [in:] Lisken, Denninger, Fußnote 39, S. 1343.

114 Ossenbühl, Cornils, Fußnote 4, S. 111.

115 Sprau, [in:] Palandt, Fußnote 77, § 839 Rn. 78.

116 Tremml, Karger, Luber, Fußnote 35, S. 56.
} 
der Differenz zwischen zwei Güterlagen. Er ist durch einen Vergleich zwischen der tatsächlichen, durch das Schadensereignis geschaffenen und der hypothetischen, d.h. unter Ausschaltung dieses Ereignisses gedachten Vermögenslage $\mathrm{zu}$ ermitteln ${ }^{117}$. $\mathrm{Zu}$ ersetzen ist damit allein das negative Interesse ${ }^{118}$.

Es wird der gesamte, unmittelbar oder mittelbar verursachte Vermögensschaden ersetzt. Darunter ist grundsätzlich auch der entgangene Gewinn gemäß § 252 BGB zu verstehen. Der Schadensbegriff unterliegt jedoch einer gewissen sachlichen Begrenzung. Als Schaden gilt nur diejenige Vermögenseinbuße, die vom sachlichen Schutzzweck der Rechtsnorm gedeckt ist ${ }^{119}$. Im Schaden muss sich damit die Gefahr verwirklicht haben, $\mathrm{zu}$ deren Abwendung die verletzte Norm erlassen worden ist ${ }^{120}$.

Ansprüche aus der Amtshaftung beinhalten neben der Verpflichtung des Staates zur Geldleistung unter bestimmten Voraussetzungen auch die Pflicht zur Abfindung in Kapital. Dies ist dann der Fall, wenn die schädigende Maßnahme die Aufhebung oder Minderung der Erwerbsfähigkeit, eine Vermehrung der Bedürfnisse oder den Verlust oder Beeinträchtigung eines Rechts auf Unterhalt hat ${ }^{121}$.

Hervorzuheben ist, dass der Amtshaftungsanspruch auch den Ersatz von immateriellen Schäden umfasst. Folglich können Beeinträchtigungen jedes der durch § 823 BGB geschützten Rechtsgüter einen Schmerzensgeldanspruch auslösen ${ }^{122}$. Dieser Schmerzensgeldanspruch kann bei verschiedenen rechtswidrigen Beeinträchtigungen geltend gemacht werden. Die Rechtsprechung hat im folgenden Fall einen Schmerzensgeldanspruch bejaht ${ }^{123}$.

Anlässlich einer Polizeiaktion wurden der Kläger sowie 400 andere Personen in einem Jugendzentrum zur Durchführung einer erkennungsdienstlichen Behandlung (Razzia) zwei Stunden lang festgehalten. Die vernommenen Personen haben sich im Jugendzentrum versammelt, um über die Räumung von besetzten Häusern zu diskutieren. Die Polizei hatte zuvor einen gerichtlichen Durchsuchungsbefehl des zuständigen Amtsgerichts erwirkt.

Das LG Göttingen hat in seinem Urteil dem Schmerzensgeldanspruch

17 C. Grüneberg, [in:] Palandt, Fußnote 77, Vorb v § 249 Rn. 10.

118 BGHZ 78, 274.

119 Dagtoglou, [in:] BoKo, Fußnote 18, Art. 34 Rn. 216 ff.

120 OLG Oldenburg, Neue Zeitschrift für Verwaltungsrecht-Rechtsprechungs-Report (NVwZ-RR) 1993, 593.

121 Rachor, [in:] Lisken, Denninger, Fußnote 39, S. 1344.

122 Ibidem, S. 1345.

123 LG Göttingen, Urteil vom 30.01.1990, 2 O 322/89. 
des Klägers stattgegeben. Die bei dieser Aktion beteiligten Beamten haben schuldhaft die ihnen gegenüber dem Kläger obliegenden Amtspflichten verletzt, indem sie ihm rechtswidrig seine Freiheit entzogen und ohne eine gesetzliche Grundlage Maßnahmen der Identitätsfeststellung, erkennungsdienstlichen Behandlung und körperlichen Durchsuchung durchgeführt haben. Das Gericht begründete den Schmerzensgeldanspruch hautsächlich mit einer fehlenden Rechtfertigungsgrundlage des Polizeieinsatzes. Vorliegend hat es sich offenkundig um eine Versammlung gemäß Art. 8 GG gehandelt, die nur unter den engen Voraussetzungen des Versammlungsgesetzes hätte beendet werden dürfen. Die für den Polizeieinsatz Verantwortlichen haben zumindest fahrlässig verkannt, dass eine Versammlung vorlag, bei der ein polizeiliches Einschreiten nur unter sehr engen Voraussetzungen möglich war. Sollten die Beamten tatsächlich die Vorschriften des Versammlungsgesetzes nicht gekannt haben bzw. fälschlich davon ausgegangen sein, dass diese gesetzlichen Bestimmungen nicht anzuwenden waren, so ist ihnen zumindest zur Last zu legen, dass sie die Voraussetzungen des Einsatzes nicht mit der gebotenen Sorgfalt überprüft und die entsprechenden Konsequenzen gezogen haben. Die Beachtung der Gesetze und sonstigen Rechtsvorschriften bei der Erfüllung ihrer öffentlichen Aufgaben ist Grundvoraussetzung für die Tätigkeit aller Amtsträger. Vorliegend hätte ein pflichtgetreuer Durchschnittsbeamter im Polizeidienst, bei dem zumindest die Kenntnis der grundlegenden Bestimmungen des Versammlungsgesetzes erwartet werden muss, ohne Weiteres erkennen können, dass bei der Durchführung der polizeilichen Maßnahme die Voraussetzungen dieses Gesetzes tangiert waren und die Versammlung dem Schutzbereich des Art. 8 GG unterfiel. Dass derartige Überlegungen entweder nicht angestellt oder zumindest verdrängt worden sind, ist dem beklagten Land als schuldhafte Amtspflichtverletzung seiner handelnden Organe zuzurechnen. Eine Entlastung kommt nicht in Betracht, weil es sich weder um besonders abgelegene Rechtsvorschriften handelte noch Gesetzesbestimmungen von sekundärer Bedeutung betroffen waren. Es ging vielmehr um die Beachtung elementarer Vorschriften, deren Berücksichtigung für die gesetzeskonforme Wahrnehmung polizeilicher Aufgaben unabdingbar ist.

Da nach § 253 II BGB bei einem Eingriff in die persönliche Freiheit grundsätzlich auch der immaterielle Schaden zu ersetzen ist und nach der Rechtsprechung ein Schmerzensgeld auch bei schwerwiegenden Verletzungen des allgemeinen Persönlichkeitsrechts verlangt werden kann, 
liegen die Voraussetzungen für einen Schmerzensgeldanspruch vor. Dieser Anspruch entfällt auch nicht deshalb, weil es sich, wie das beklagte Land meint, um einen Bagatelleingriff handelt, der trotz der tatbestandlichen Verwirkung des Schmerzensgeldanspruchs hinzunehmen sein könnte. Bei Berücksichtigung sämtlicher Umstände des Polizeieinsatzes muss davon ausgegangen werden, dass die Grenze zum hinzunehmenden Bagatelleingriff deutlich überschritten ist. Hierunter zählen die Umstände, dass der Kläger über zwei Stunden mit 400 weiteren Personen und einer erheblichen Anzahl von Polizeibeamten in einem für derartig große Personenansammlungen kaum ausgelegten Haus zusammengepfercht war und so seine unmittelbare Bewegungsfreiheit stark eingeschränkt wurde. Hinzu kamen eine nur bei dem Vorliegen konkreter Verdachtsmomente, für die das beklagte Land nichts vorgetragen hat, gerechtfertigte erkennungsdienstliche Behandlung sowie die überzogene Personenfeststellung mit der Anfertigung von Lichtbildern und der körperlichen Durchsuchung des Kläger, die bei der Durchführung einer typischen Razzia nicht üblich sein dürften.

Dagegen hat das OLG Koblenz in einem anderen Fall ${ }^{124}$ den Schmerzensgeldanspruch abgewiesen. Der Kläger wurde aufgrund eines Verdachts, dass er sich in einem alkoholisierten Zustand befände, auf eine Polizeiwache gebracht. Anschließend wurde mittels Zwangsmaßnahmen sein Blutalkoholgehalt überprüft. Der Kläger wurde auf der Wache unfreiwillig eineinhalb Stunden zur Durchführung der oben beschriebenen Maßnahmen festgehalten.

Das Gericht hat eindeutig festgestellt, dass der unfreiwillige eineinhalbstündige Aufenthalt auf einer Polizeidienststelle eines Rechtsstaates zum Zweck der Personalienfeststellung und -aufnahme sowie Durchführung einer Überprüfung auf Alkohol keine seelischen Unlustgefühle aufkommen lässt, die eines materiellen Ausgleichs bedürfen. Vorliegend fehlte es bereits an einer einschlägigen Amtspflichtverletzung der Polizeibeamten. Ein Schmerzensgeldanspruch wäre jedoch auch dann zu verneinen, wenn diese Freiheitsbeschränkung rechtswidrig gewesen wäre. In diesem Fall hätte es sich aufgrund der Gesamtumstände lediglich um eine Bagatellbeschränkung gehandelt, die der betroffenen Bürger grundsätzlich hinzunehmen hat.

$\overline{124}$ OLG Koblenz, Urteil vom 30.06.1999, 1 U 1285/96. 


\section{HAFTUNGSAUSSCHLUSS UND HAFTUNGSBEGRENZUNG}

\subsection{Mitverschulden}

Im Hinblick auf die von der Polizei vorgenommenen Maßnahmen in Ausübung der öffentlichen Gewalt sind bestimmte haftungsmodifizierende Regelungen von Bedeutung. Gemäß § 254 BGB führt die schuldhafte Mitverursachung eines Schadens $\mathrm{zu}$ einer Anspruchsminderung. Die beschränkende Regelung des § 254 BGB findet nur dann Anwendung, wenn die Sondervorschrift des § 839 III BGB nicht einschlägig ist. Das "Mitverschulden“ im Sinne des § 254 BGB ist der vorwerfbare Verstoß gegen Gebote des eigenen Interesses ${ }^{125}$. Diese Regelung beruht auf dem Rechtsgedanken, dass derjenige, der die Sorgfalt außer Acht lässt, die nach der Lage der Sache erforderlich erscheint, um sich selbst vor Schaden zu bewahren, den Verlust oder die Kürzung seines Anspruchs hinnehmen muss $^{126}$.

In diesem Sinne hat das OLG Hamm die Beschränkung eines Ersatzanspruches eines Geschädigten vorgenommen ${ }^{127}$. Der Kläger hat während eines Besuchs einer Gaststätte in einem stark alkoholisierten Zustand Gäste sowie den Gastwirt belästigt und beleidigt. Die daraufhin angeforderten Polizeibeamten haben dem Kläger einen Platzverweis ausgesprochen und ihn aufgefordert, die Gaststätte zu verlassen. Der Kläger hat sich dem tätlich widersetzt. Die Polizeibeamten haben den Platzverweis durch Anwendung unmittelbaren Zwangs durchgesetzt. Als sie den Kläger zu Boden warfen und ihm anschließend Fesseln anlegen wollten, erlitt der Kläger eine schwerwiegende Verletzung im Halsbereich. Er erlitt eine dauerhafte Querschnittslähmung, die durch die polizeilichen Würge- und Haltegriffe verursacht wurde.

Das Gericht stellte eine durch die Polizeibeamten fahrlässig begangene Amtspflichtverletzung fest. Die Beamten waren zwar dazu berechtigt, gegenüber dem Kläger aufgrund der Gesamtumstände (Gegenwehr des Klägers) unmittelbaren Zwang auszuüben. Bei der Gewaltanwendung wurde jedoch der Grundsatz der Verhältnismäßigkeit außer Acht gelassen. Eine derart massive Gewaltanwendung war trotz des renitenten Verhaltens des Klägers nicht erforderlich.

Der Kläger muss sich jedoch ein erhebliches Mitverschulden an der Schadensentstehung gemäß § 254 I BGB zurechnen lassen. Dieses folgt

125 Rachor, [in:] Lisken, Denninger, Fußnote 39, S. 1348.

126 BGHZ 45, 290 (254).

127 OLG Hamm, Urteil vom 27.05.2009, Az. 11 U 175/07. 
daraus, dass die pflichtwidrige Gewaltanwendung der Polizeibeamten durch das vorangehende Verhalten des Klägers verursacht wurde. Dem Ansatz eines Mitverschuldens steht nicht entgegen, dass ein Verletzter im Allgemeinen auf die Rechtsmäßigkeit der ihm gegenüber vorgenommenen Amtshandlungen vertrauen darf. Er handelt nur dann vorwerfbar, wenn er nicht das ihm zumutbare Maß an Aufmerksamkeit und Sorgfalt bei der Besorgung eigener Angelegenheiten aufgewendet oder im Rahmen des Zumutbaren alles zur Vermeidung von Schwierigkeiten getan hat. In dem vorliegenden Fall ergibt die gebotene wertende Betrachtung, dass der Verursachungsbeitrag des Klägers als Geschädigten nicht außerhalb der Grenze liegt, bis zu welcher ihm eine Mithaftung für seine Folgen billigerweise und bei vernünftiger Betrachtung zugemutet werden kann. Durch sein erhebliches, verbales wie tätliches Eindringen auf die Polizisten hat der Kläger in beträchtlichem Maße die Gefahr erhöht, dass die Polizisten ihm gegenüber Gewalt anwenden würden und dabei unwillentlich die Grenzen des Erlaubten überschreiten könnten. Allen Versuchen, ihn ohne Anwendung von Gewalt aus der Gaststätte zu bringen und seine Rückkehr zu verhindern, hatte sich der Kläger widersetzt. Letztlich ließ er durch sein Verhalten den Polizisten keine andere Wahl als eine nicht unerhebliche Gewaltanwendung, welche er damit herausgefordert hatte. Den Kläger entlastet dabei seine beträchtliche Alkoholisierung nicht, da dem Ausschluss seiner Mitverantwortlichkeit der § 827 Satz 2 BGB entgegensteht.

Bei der Abwägung der beiderseitigen Verschuldensanteile ergibt sich ein gleichwertiges Verschulden auf beiden Seiten. Deshalb kann derjenige, der aufgrund eines an sich rechtmäßigen Einschreitens der Polizei unter Einsatz körperlicher Gewalt veranlasst hat, grundsätzlich nur einen Teil des ihm durch übermäßig hartes, und damit rechtswidriges, Vorgehen der Beamten entstandenen Schadens ersetzt verlangen. Sowohl die massiv übertriebene Gewaltanwendung durch die Polizeibeamten als auch das vorangegangene renitente und provokante Verhalten des Klägers beinhalten jeweils ein grobes Fehlverhalten von erheblichem Gewicht.

\subsection{Rechtsmittelversäumnis}

Als weitere Ausprägung des $\S 254$ BGB kann auch die Verpflichtung des Bürgers gesehen werden, den Schaden durch Einlegung von Rechtsmitteln zu verhindern oder zu verringern. Der Vorrang des Primärrechtsschutzes 
ist im Bereich des Amtshaftungsrechts ausdrücklich in § 839 III BGB geregelt. Anzumerken ist jedoch, dass diese Regelung für die (Vollzugs-) Polizei von geringer praktischer Bedeutung ist. Polizeimaßnahmen werden grundsätzlich sofort vollzogen und ihre schädigenden Folgen können durch die Einlegung von Rechtsbehelfen nicht abgewandt werden ${ }^{128}$.

\subsection{Verweisungsprivileg}

Gemäß § 839 ISatz 2 BGB kann der Amtswalter, dem nur ein fahrlässiges Verschulden vorwerfbar ist, nur dann in Anspruch genommen werden, wenn der Geschädigte nicht auf andere Weise Ersatz erlangen kann. Die originäre Existenzberechtigung des sog. Verweisungsprivilegs hat ursprünglich dem Schutz des einzelnen Beamten gedient. Wegen der durch Art. 34 GG eingeführten Haftungsübernahme durch den Staat ist jedoch eine solche Limitierung des Haftungsumfangs rechtspolitisch obsolet ${ }^{129}$. Der Anwendungsbereich der Subsidiaritätsklausel wird deshalb von der Rechtsprechung zunehmend eingeschränkt. Danach gilt beispielsweise das Verweisungsprivileg nicht, wenn sich der anderweitige Anspruch gegen einen Verwaltungsträger richtet oder wenn Versorgungsansprüche gegen gesetzliche oder private Krankenversicherungen bestehen ${ }^{130}$. Das Verweisungsprivileg erfährt eine teleologische Reduktion ebenfalls bei Schäden, dieein vonder Polizei zur Durchführung polizeilicher Maßnahmen beauftragter Unternehmer verursacht hat. Als Beispiel dienen vor allem Fälle des polizeilich angeordneten Abschleppens von Fahrzeugen. Auch dann muss sich nämlich der Geschädigte nicht auf Ansprüche gegen den Unternehmer verweisen lassen. Der Unternehmer haftet gegenüber dem Bürger nicht neben dem Staat, sondern überhaupt nicht ${ }^{131}$.

\section{PASSIVLEGITIMATION}

Bei Amtshaftungsansprüchen ist nach ständiger Rechtsprechung des BGH grundsätzlich die Anstellungskörperschaft des Polizeibeamten Antragsgegner ${ }^{132}$. Anstellungskörperschaft von Landespolizeibeamten ist das jeweilige Land. In Brandenburg ist dies für den Polizeivollzugsdient im § 109 BbgLBG geregelt. Anstellungskörperschaft von

\footnotetext{
Rachor, [in:] Lisken, Denninger, Fußnote 39, S. 1349.

Ossenbühl, Cornils, Fußnote 4, S. 81 f.

Papier, [in:] MüKo, Fußnote 5, § 839 Rn. 262 ff.

131 Rachor, [in:] Lisken, Denninger, Fußnote 39, S. 1344.

132 Ibidem, S. 1353.
} 
Bundespolizeibeamten ist die Bundesrepublik Deutschland. Von diesem Grundsatz muss aber abgewichen werden, wenn ein Polizeibeamter aus einem anderen Bundesland tätig ist. Dies gilt im Fall der gegenseitigen polizeilichen Unterstützung, wie sie etwa bei Großdemonstrationen in Anspruch genommen wird. Gemäß $§ 7$ II $2 \mathrm{BbgPOG}^{133}$ gelten dieMaßnahmen der jeweiligen Polizisten als Maßnahmen derjenigen Polizeibehörde, in deren örtlichen und sachlichen Zuständigkeitsbereich sie tätig geworden sind. Der Geschädigte wendet sich deshalb als Anspruchsgegner an das jeweilige Bundesland, in dem das schädigende Ereignis stattgefunden hat $^{134}$.

\section{VERJÄHRUNG DER RECHTSANSPRÜCHE}

Für Ansprüche aus Amtspflichtverletzung gilt die regelmäßige Verjährungsfrist von 3 Jahren gemäß § 195 BGB. Nach § 199 BGB beginnt sie mit dem Schluss des Jahres, in dem der Anspruch entstanden ist und der Gläubiger von den den Anspruch begründenden Umständen und der Person des Schuldners Kenntnis erlangt oder ohne grobe Fahrlässigkeit erlangen müsste. DieKenntnis ist vorhanden, wenn aufgrund der bekannten Tatsachen der Anspruch gegen eine bestimmte Person im Wege der Klage mit hinreichender Aussicht auf Erfolg geltend gemacht werden kann und dem Geschädigten damit zuzumuten ist ${ }^{135}$. Gemäß § 199 II, III BGB sieht das Gesetz bei fehlender Kenntnis oder nicht vorwerfbarer Unkenntnis absolute Höchstfristen vor. Entsprechend verjähren Schadensersatzansprüche, die auf der Verletzung des Lebens, des Körpers, der Gesundheit oder der Freiheit beruhen, nach 30 Jahren ab der Begehung der Handlung, der Pflichtverletzung oder dem sonstigen, den Schaden auslösenden Ereignis. Sonstige Ansprüche verjähren regelmäßig mit Ablauf von 10 Jahren.

\section{SCHADENSBERECHTIGTE}

Im Hinblick auf den Kreis der Schadenberechtigten ist auf das Tatbestandmerkmal der Drittbezogenheit der Amtspflichten zu verweisen. Demnach ist aktivlegitimiert, wer materiell-rechtlich berechtigt ist. Als „Dritter“ wird jeder klassifiziert, dessen Interessen die Amtspflicht schützen

133 Gesetz über die Aufgaben, Befugnisse, Organisation und Zuständigkeit der Polizei im Land Brandenburg (Brandenburgisches Polizeigesetz - BbgPolG) vom 19.03.1996 (GVBl.I/96, [Nr. 07], S.74) zuletzt geändert durch Gesetz vom 28.04.2014 (GVBl.I/14, [Nr. 20]).

134 Rachor, [in:] Lisken, Denninger, Fußnote 39, S. 1350.

135 Ibidem, S. 1353. 
soll und in dessen Rechtskreis durch die Amtspflichtverletzung eingegriffen wird. $\mathrm{Zu}$ den geschützten „Dritten“ zählen alle natürlichen Personen, darunter auch die im öffentlichen Dienst Beschäftigten wie etwa Beamte ${ }^{136}$. Auch eine juristische Person des öffentlichen Rechts kann „Dritter" sein. Dies setzt voraus, dass die juristische Person dem handelnden Amtsträger in einer Weise gegenüber steht, wie es für das Verhältnis zwischen dem Dienstherrn und dem Bürger charakteristisch ist. Sie muss entsprechend einer Rechtsstellung eines Privaten dem schädigende Amtswalter quasi als "Gegner" gegenüber stehen ${ }^{137}$.

\section{SPEZIALGESETZLICHE ANSPRUCHSNORMEN FÜR RECHTSWIDRIGE MASSNAHMEN DER POLIZEI}

\section{POLIZEIGESETZLICHE UNRECHTSHAFTUNG}

Die Haftung für rechtswidrige polizeiliche Maßnahmen beschränkt sich nicht nur auf den Amtshaftungsanspruch. Rechtswidrige Maßnahmen des Staates können neben Ersatzansprüchen aus der Amtshaftung parallel Ausgleichsansprüche nach speziellen Bestimmungen der Polizeigesetze und des Strafverfolgungsentschädigungsgesetzes auslösen.

\section{EINGRIFFSHAFTUNG DER POLIZEI IM RAHMEN DER POLIZEI- UND ORDNUNGSGESETZE}

Die Entschädigungstatbestände im Rahmen der polizeilichen Gefahrenabwehr sind in den einschlägigen Polizeigesetzen niedergelegt. Aufgrund des deutschen Staatsorganisationsrechts steht dem Bund keine Regelungskompetenz im Bereich der allgemeinen polizeilichen Gefahrenabwehr $\mathrm{zu}^{138}$. Die Berücksichtigung aller landesrechtlichen Bestimmungen von polizeilichen Ausgleichsansprüchen würde den Rahmen dieses Beitrags sprengen. Vor diesem Hintergrund werde ich die polizeigesetzliche Unrechtshaftung am Beispiel des brandenburgischen Polizeigesetztes und des brandenburgischen Ordnungsgesetzes behandeln. Einen verschuldensunabhängigen Entschädigungsanspruch in Fällen einer rechtswidrigen Maßnahme gewährt in Brandenburg ausdrücklich der

\footnotetext{
136 Sprau, [in:] Palandt, Fußnote 77, § 839 Rn. 47.

137 C. Muthers, [in:] B. Dauner-Lieb, W. Langen, BGB-Schuldrecht, Band 2, Baden-Baden 2012, $\S 831 \mathrm{Rn} .131$.

138 Vgl. E. Denninger, R. Poscher, [in:] Lisken, Denninger, Fußnote 39, S. 114.
} 
§ 38 I lit. b BbgOBG ${ }^{139}$. Der § 39 V BbgOBG statuiert, dass spezialgesetzliche polizeirechtliche Ansprüche etwaige Amtshaftungsansprüche unberührt lassen.

Grundsätzlich enthält das BbgOBG in den §§ 38-42 Regelungen in Bezug auf Ersatzansprüche gegen die Ordnungsbehörden. Die Transformationsnorm des $\$ 70$ BbgPolG erklärt diese Normen entsprechend anwendbar für Entschädigungsansprüche gegen die Polizeibehörde. Entsprechend besteht eine einheitliche Haftung für die gesamten Gefahrenabwehrbehörden.

\subsection{Tatbestandliche Haftungsvoraussetzung}

Voraussetzung für einen Ersatzanspruch des Geschädigten nach § 38 I lit. b BbgOBG ist zunächst, dass jemandem ein Schaden durch rechtswidrige Maßnahmen einer Gefahrenabwehrbehörde entstanden ist.

\subsubsection{Maßnahme}

Der Begriff der Maßnahme wird sehr weit gefasst und berücksichtigt jeden Erfolg, welcher durch ein behördliches Handeln oder pflichtwidriges Unterlassen bewirkt wird ${ }^{140}$. Dazu zählt sowohl rechtliches wie faktisches Handeln, Eingriffe und nicht eingreifendes Tätigwerden ${ }^{141}$. Diese Interpretationsweise findet auch eine Grundlage in der Wortwahl des Gesetzgebers. Der Gesetzgeber verwandte insofern zur Kennzeichnung des ordnungsbehördlichen Handelns die allgemeine Bezeichnung "Maßnahme“ in Abweichung zu dem zuvor die Rechtsprechung prägenden und weitaus enger gefassten Begriff des „Eingriffs “142. Besonders hervorzuheben es gilt jedoch, dass von einer Maßnahme nur dann gesprochen werden kann, wenn eine Handlung der Behörde vorliegt. Die Anknüpfung an den Begriff der Maßnahme in § 38 I BbgOBG bedeutet, dass ein rechtswidriges Unterlassen keine Ausgleichsansprüche auf der Grundlage der polizeigesetzlichen Haftungstatbestände auslöst. Grundlegende Anspruchsvoraussetzung ist vielmehr das Handeln der

\footnotetext{
139 Gesetz über Aufbau und Befugnisse der Ordnungsbehörden (Ordnungsbehördengesetz - OBG), in der Fassung der Bekanntmachung vom 21.08.1996 (GVBl.I/96, [Nr. 21], S.266) zuletzt geändert durch Gesetz vom 20.12.2010 (GVBl.I/10, [Nr. 47]).

140 Vgl. Ossenbühl, Cornils, Fußnote 4, S. 517.

141 B. Pieroth, B. Schlink, M. Kniesel, Polizei- und Ordnungsrecht, München 2012, S. 417.

142 Vgl. H.H. Kasten, Die Haftung der Ordnungsbehörden, Juristische Schulung (JuS) 1986, S. 451.
} 
Behörde ${ }^{143}$. Ein reines Unterlassen oder Untätigbleiben hat nach ständiger Rechtsprechung des BGH grundsätzlich keine Eingriffsqualität, selbst wenn eine Rechtspflicht zum Handeln besteht ${ }^{144}$.

\subsubsection{Rechtswidrigkeit der Maßnahme}

Hierbei ist es gleichgültig, ob die Ordnungsbehörde ein Verschulden trifft oder nicht. Der $\S 38$ I lit. b BbgOBG sieht eine staatliche Gefährdungshaftung für die rechtswidrige polizeiliche Inanspruchnahme vor $^{145}$. Eine Maßnahme gilt dann als rechtswidrig, wenn sie mit dem objektiven Recht in Widerspruch steht. Die Rechtswidrigkeit kann sich damit grundsätzlich aus jeder Rechtsnorm ergeben. Maßgeblich für die Beurteilung der Rechtsmäßigkeit einer polizeilichen Maßnahme ist allein, ob die einfachgesetzlichen und verfassungsrechtlichen Handlungsvoraussetzungen zum Zeitpunkt des Einschreitens vorlagen. Kann dies bejaht werden, dann ist auch bei unvorhergesehenen und unvorhersehbaren Schädigungen eines Unbeteiligten kein Raum für die Anwendung der Vorschriften über die polizeiliche Unrechtshaftung ${ }^{146}$.

\subsubsection{Kausaler Schaden}

Die Regelung des §39 I lit. b BbgOBG knüpft die Entschädigungspflicht an die Rechtswidrigkeit der behördlichen Maßnahme. Die Rechtswidrigkeit der Maßnahme muss kausal für den an den Rechtsgütern eingetretenen Schaden sein. Es muss daher ein Pflichtwidrigkeitszusammenhang bestehen. Entschädigungsansprüche scheiden folglich aus, wenn sich die handelnde Behörde rechtmäßig verhalten hätte und der eingetretene Schaden dennoch eingetreten wäre. Zu den Anforderungen an dieKausalität gelten die allgemeinen Grundsätze des Deliktsrechts ${ }^{147}$. Wie im Rahmen der Kausalitätsfrage im Fall der Amtshaftung wird die Bedingungstheorie (conditio-sine-qua-non) um das wertende Kriterium der Adäquanz ergänzt. Dies hat zur Folge, dass ganz entfernt liegende Beeinträchtigungen zu

\footnotetext{
143 Vgl. Ossenbühl, Cornils, Fußnote 4, S. 518.

144 Vgl. BGH Neue Juristische Wochenschrift 1985, 1287; BGHZ 12, 53 (56); 32, 208 (211);

56, 40 (42); 102, 350 (364).

145 C. Gusy, Polizei- und Ordnungsrecht, Tübingen 2014, S. 304.

146 Rachor, [in:] Lisken, Denninger, Fußnote 39, S. 1328.

147 K.O. Bergmann, H. Schumacher, Die Kommunalhaftung, Köln 2006, Rn. 1507.
} 
einer Entschädigung nicht ausreichen. Zugerechnet werden nur adäquat kausale Schäden.

\subsubsection{Schutzzweck der Norm}

Ähnlich wie im Rahmen der Amtshaftung ergänzt die Rechtsprechung die Tatbestandsvoraussetzungen des § 39 I lit. b BbgOBG um das ungeschriebene Tatbestandsmerkmal des Schutzzwecks der Norm. Dies hat zur Folge, dass die Verletzung von Normen, die dem Bürger keine individuell geschützte Rechtsposition gewähren, keinen Ersatzanspruch des Bürgers auslöst ${ }^{148}$. Insoweit ist der Schutzbereich der Ersatznorm eingeschränkt. DiediesemBeitrag zugrundeliegenden polizeilichen Normen bezwecken jedoch im Regelfall nicht nur allein den Schutz des öffentlichen Interesses, sondern haben gleichzeitig einen Individualrechtsschutz des Bürgers zum Ziel. Im Ergebnis wird der individuell begünstigende Schutzzweck der polizeilichen Normen bejaht.

\subsection{Einwendungen}

Wie der Amtshaftungsanspruch unterliegt der Anspruch nach § 38 I BbgOBG jedoch bestimmten Einschränkungen. Gemäß § 38 II lit. a BbgOBG ist ein Anspruch ausgeschlossen, wenn der Geschädigte auf andere Weise Ersatz erlangt hat. Maßgeblich ist, dass nicht lediglich ein Anspruch des Geschädigten besteht, sondern dass der Geschädigte tatsächlich einen Ersatz erlangt hat. Dies kann sowohl ein Versicherungsvertrag als auch ein privatrechtlicher Ersatzanspruch sein. Es handelt sich insoweit um einen subsidiären Anspruch.

Nach § 38 II lit. b BbgOBG ist ein Anspruch ebenfalls ausgeschlossen, wenn durch die schadensverursachende Maßnahme die Person oder das Vermögen des Geschädigten geschützt worden ist. In diesem Sinne hat die schädigende Maßnahme dem Geschädigten gleichzeitig einen Vorteil gebracht. Damit realisiert sich in der obigen Vorschrift der Gedanke der Vorteilsanrechnung.

Die Anwendung dieser Vorschrift ist besonders in Fällen problematisch, in denen ein Amtswalter ex ante von einer Gefahrenlage ausgeht und sich ex post herausstellt, dass die Gefahr nie vorgelegen hat. Es stellt sich dann nämlich die Frage, ob die Person oder ihr Vermögen durch diese Maßnahme tatsächlich geschützt worden sind. Einerseits lässt sich auf die tatsächlichen

148 Vgl. Kasten, Fußnote 142, S. 453. 
Verhältnisse abstellen und ex post feststellen, dass objektiv zu keinem Zeitpunkt eine Gefahr bestand und damit auch kein Schutz vor einer Gefahr erzielt werden konnte ${ }^{149}$. Im Ergebnis stünde der § 38 II lit. b BbgOBG dem Entschädigungsanspruch nicht entgegen. Diese Ansicht bestätigt auch der Wortlaut der brandenburgischen Klausel, der objektiv gefasst ist. Es kommt nach dem Wortlaut nicht darauf an, dass die Maßnahme den Schutz des Geschädigten bezweckt hat. Vielmehr wird objektiv darauf abgestellt, dass der Geschädigte durch die Maßnahme tatsächlich geschützt worden ist. Dieses Ergebnis ist im Übrigen mit der teleologischen Auslegung zu vereinbaren ${ }^{150}$. Dies ist nur dann gegeben, wenn der Geschädigte durch den Polizeieinsatz vor einem weitaus größeren Schaden bewahrt wurde. Der Vorteil kann den erlittenen Schaden in Ausnahmefällen sogar dermaßen überwiegen, dass der Ersatzanspruch ganz auszuschließen ist ${ }^{151}$.

\subsection{Inhalt und Umfang des Entschädigungsanspruchs}

Der Schadensausgleich des Polizei- und Ordnungsrechts ist nicht auf Naturalrestitution im Sinne eines vollumfänglichen Schadensersatzes, sondern allein auf geldwerte Entschädigung gerichtet und soll dem Anspruchsinhaber einen angemessenen Vermögensausgleich gewährleisten ${ }^{152}$. Maßgeblich ist grundsätzlich nur der Verkehrswert der entzogenen Substanz, nicht aber der entgangene Gewinn bzw. eine hypothetische Vermögensentwicklung ${ }^{153}$.

Damit ist der Ersatz von immateriellen Schäden, wie z.B. ein Anspruch auf Schmerzensgeld, ausgeschlossen. Dagegen zählen expressis verbis zum Vermögensschaden nach § 39 II Satz 2 BbgOBG auch die Kosten für gestiegene Bedürfnisse oder der Ausgleich geminderter Erwerbsfähigkeit.

Darüber hinaus sind nur unmittelbare Schäden ersatzfähig. Es muss ein unmittelbarer Zusammenhang zwischen der hoheitlichen Maßnahme und dem jeweiligen Vermögensschaden bestehen. Nötig ist ein innerer Zusammenhang mit dieser Maßnahme. Es muss sich daher eine besondere Gefahr verwirklichen, die bereits in der hoheitlichen Maßnahme selbst angelegt ist ${ }^{154}$. Eine Unmittelbarkeit der Schadensverursachung ist gerade

\footnotetext{
149 Vgl. H.M. Wolffgang, M. Hendricks, M. Merz, Polizei- und Ordnungsrecht in NRW, München 2011, S. 171.

150 Vgl. F. Schoch, Kosten der Gefahrenabwehr und Ersatzansprüche gegen die Verwaltung, Juristische Schulung (JuS) 1995, 510.

151 Ossenbühl, Cornils, Fußnote 4, S. 526.

152 Vgl. Wolffgang, Hendricks, Merz, Fußnote 150, S. 171.

153 F. Ossenbühl, Neuere Entwicklungen im Staatshaftungsrecht, Berlin 1984, S. 28.

154 BGHZ 131, 163 (166).
} 
dann anzunehmen, wenn sich Schäden typischerweise aus der behördlichen Maßnahme ergeben. Tritt der Schaden erst aufgrund weiterer Umstände ein, so fehlt es an der Unmittelbarkeit ${ }^{155}$. Das zusätzliche Kriterium der unmittelbaren Verursachung bedeutet im Ergebnis eine deutliche Verschärfung des Kausalitätsnachweises.

Im Rahmen zu entschädigender Einkommenseinbußen ist regelmäßig nur der gewöhnliche Verdienst oder Nutzungsausfall zu entschädigen. Ein über den Ausfall des gewöhnlichen Verdienstes hinausgehender entgangener Gewinn wird gemäß § 39 I Satz 2 BbgOBG nur dann ausnahmsweise entschädigt, wenn dies zur Abwendung unbilliger Härten geboten erscheint.

Auch ein Mitverschulden ist gemäß § 39 IV BbgOBG bei der Berechnung des Schadens in Ansatz zu bringen. Hierbei wird der Grad des Verschuldens wie beim Amtshaftungsanspruch im Sinne des § 254 BGB mitberücksichtigt.

\subsection{Verjährung des Entschädigungsanspruchs}

Das brandenburgische Polizeigesetz hat für den Bereich der Ausgleichsansprüche die ebenfalls für die Amtshaftung geltenden Verjährungsvorschriften des BGB übernommen. Entsprechend bestimmt $\S 40 \mathrm{BbgOBG}$ die regelmäßige Verjährungsfrist auf drei Jahre ab dem Zeitpunkt, in welchem der Geschädigte von dem Schaden und von der zur Entschädigung verpflichteten Körperschaft Kenntnis erlangt hat. Ohne diese Kenntnis verjährt der Anspruch spätestens mit Ablauf von 30 Jahren.

\subsection{Aktivlegitimation, Rechtsweg, Anspruchsgegner}

In Fällen rechtswidrigen Vorgehens von Polizeibehörden ist der jeweils Betroffene Anspruchsinhaber und damit aktivlegitimiert. Hierbei ist es vollkommen gleich, ob der Betroffene als Störer, Nichtstörer, Unbeteiligter oder "Jedermann" in Anspruch genommen wurde ${ }^{156}$.

Der brandenburgische Gesetzgeber hat von der Ermächtigung in $\S 40$ I Satz $2 \mathrm{VwGO}^{157}$ Gebrauch gemacht und für die polizeilichen

\footnotetext{
155 M. Möller, J. Wilhelm, Allgemeines Polizei- und Ordnungsrecht, Stuttgart 2003, S. 222.

156 Rachor, [in:] Lisken, Denninger, Fußnote 39, S. 1336.

157 Verwaltungsgerichtsordnung in der Fassung der Bekanntmachung vom 19.03.1991 (BGBl. I S. 686), die zuletzt durch Artikel 7 des Gesetzes vom 20.10.2015 (BGBl. I S. 1722) geändert worden ist.
} 
Ausgleichsansprüche gemäß § 75 BbgPolG den ordentlichen Rechtsweg eröffnet. Gemäß § 41 BbgOBG ist grundsätzlich das Land Brandenburg als Anstellungskörperschaft der Polizeibeamten ausgleichspflichtig. Ausnahmen sind wie im Falle der Amtshaftungsklage nur dann gegeben, wenn z.B. gegenseitige Unterstützungen von Polizeieinheiten über die Ländergrenzen hinaus erfolgen.

\section{KONKURRENZ ZWISCHEN DER AMTSHAFTUNG UND DEM POLIZEIRECHTLICHEN AUSGLEICHANSPRUCH IN BRANDENBURG}

Der polizeiliche Ausgleichanspruch ist gegenüber dem Amtshaftungsanspruch vollkommen unabhängig. Er kann, wie in § 39 BbgOBG klarstellend festgehalten, immer neben dem Amtshaftungsanspruch geltend gemacht werden ${ }^{158}$.

Weiterhin ist auf zahlreiche, auf verschiedenen Ebenen zu verortende Unterschiede zwischen der polizeilichen Ausgleichshaftung und der Amtshaftung hinzuweisen. Der elementare Unterschied ist bereits in der dogmatischen Grundkonstruktion des Haftungstatbestandes erkennbar. Der $\S 38$ I BbgOBG bestimmt eine originäre, unmittelbare Staatshaftung des Landes Brandenburg, wohingegen der Art. 34 GG i.V.m. § 839 BGB mittels einer Schuldübernahmekonstruktion die Haftung vom hoheitlich tätigen Beamten auf den Staat lediglich überleitet. Dieser strukturelle Gegensatz bedingt eine differenzierte Ausgestaltung der haftungsbegründenden Tatbestandsmerkmale. Für Fälle rechtswidriger polizeilicher Inanspruchnahme statuiert das brandenburgische Polizeigesetz bzw. Ordnungsbehördengesetz eine staatliche Gefährdungshaftung. Entsprechend folgt sie allein der Risikoerhöhung durch polizeiliches Handeln ohne Rücksicht auf Verschulden des jeweiligen Polizeibeamten. Dagegen gründet der Schadensersatzanspruch aus der Amtspflichtverletzung notwendigerweise auf dem Verschulden des jeweiligen Amtswalters. Zwar wurde das Verschuldensmerkmal durch die Rechtsprechung weitestgehend "objektiviert" und "entindividualisiert". Nach einer Erhebung des Bundesministeriums der Justiz ${ }^{159}$ sind trotzdem ca. $10,4 \%$ der ausgewerteten Staatshaftungsklagen aufgrund fehlenden Verschuldens erfolglos geblieben. Damit ist der Amtshaftungsanspruch im Vergleich zum polizeirechtlichen Ausgleichanspruch für rechtswidrige

158 Vgl. Rachor, [in:] Lisken, Denninger, Fußnote 39, S. 1356.

159 Bundesministerium der Justiz (Hrsg.), Zur Reform des Staatshaftungsrechts, Rechtstatsächliche Erkenntnisse in Staatshaftungssachen, Verwaltungserhebung und Gerichtsaktenauswertung, Bonn 1976, S. 34. 
Maßnahmen auf der Tatbestandsseite enger.

Andererseits ist der Amtshaftungsanspruch auf der Rechtsfolgenseite weiter gefasst. Der Amtshaftungsanspruch sieht gemäß § 249 I BGB grundsätzlich eine Naturalrestitution vor. Damit soll der Zustand hergestellt werden, der ohne Eintritt der schädigenden Maßnahme eingetreten wäre. Der polizeirechtliche Entschädigungsanspruch berechtigt jedoch zu keinem Schadensersatz, sondern ist lediglich auf einen angemessenen Ausgleich in Geld gerichtet. Die Wiederherstellung eines dem ursprünglichen Zustand vergleichbaren bzw. gleichwertigen Zustandes kann unter Berufung auf den Entschädigungsanspruch daher nicht verlangt werden. In beiden Schadensausgleichfällen muss eine adäquate Kausalität zwischen der Maßnahme bzw. Pflichtverletzung und dem Schaden bestehen. Hierbei bezieht sich der Begriff der Maßnahme lediglich auf tatsächlich vorgenommene Handlungen der Polizei und schließt damit eine etwaige Verantwortlichkeit für Unterlassen aus. Die Rechtswidrigkeit beurteilt sich in beiden Fällen nach den allgemeinen Maßstäben.

\section{GESETZ ÜBER DIE ENTSCHÄDIGUNG FÜR STRAFVERFOLGUNGSMAßNAHMEN}

\subsection{Formelle Voraussetzungen}

Einen weiteren spezialgesetzlich normierten Entschädigungsanspruch begründet das Gesetz über die Entschädigung für Strafverfolgungsmaßnahmen (StrEG) ${ }^{160}$. Das Gesetz will dem zu Unrecht durch eine Strafverfolgung Betroffenen Wiedergutmachung geben ${ }^{161}$. Dieses Gesetz regelt neben der in § 1 StrEG geregelten Entschädigung für Urteilsfolgen ebenfalls in $\S 2$ StrEG die polizeilich relevante Haftungssituation der Entschädigung für Strafverfolgungsmaßnahmen. Zu den Strafverfolgungsmaßnahmen zählen gemäß § 2 II StrEG neben der vorläufigen Festnahme nach $\S 127$ II StPO ${ }^{162}$ auch die strafprozessualen Maßnahmen der Sicherstellung, Beschlagnahme und der Durchsuchung. Diese Maßnahmen zeichnen sich dadurch aus, dass sie nur aufgrund eines

160 Gesetz über die Entschädigung für Strafverfolgungsmaßnahmen vom 8.03.1971 (BGB1. I S. 157), das zuletzt durch Artikel 4 des Gesetzes vom 17.07.2015 (BGBl. I S. 1332) geändert worden ist.

161 D. Wulf, Entschädigung für Strafverfolgungsmaßnahmen, Deutsche Richterzeitung (DRiZ) 1989, S. 208.

162 Strafprozessordnung in der Fassung der Bekanntmachung vom 07.04.1987 (BGBl. IS. 1074, 1319), die zuletzt durch Artikel 14 Nummer 7 des Gesetzes vom 20.10.2015 (BGBl. I S. 1722) geändert worden ist. 
qualifizierten Verdachts angeordnet und vollzogen werden. Sie kommen daher regelmäßig einer Vorwegnahme einer späteren Verurteilung nahe und greifen sehr nachhaltig in eine grundgesetzlich abgesicherte Rechtsposition ein ${ }^{163}$. Der Katalog der entschädigungsfähigen vorläufigen Strafverfolgungsmaßnahmen des § 2 StrEG ist abschließend, eine analoge Anwendung ausgeschlossen ${ }^{164}$. Unbilligkeiten, die im Zusammenhang mit anderen Maßnahmen wie z.B. einer körperliche Untersuchung oder einer Identitätsfeststellung des Beschuldigten entstanden sind, müssen grundsätzlich als Sonderopfer des Betroffenen hingenommen werden. Der Betroffene kann jedoch bei Erfüllung weiterer Voraussetzungen seinen Anspruch ggf. auf eine andere Haftungsgrundlage stützen, etwa den Amtshaftungsanspruch.

Der Entschädigungsanspruch gemäß $\S 2$ StrEG bezieht sich daher auf einen quantitativ begrenzten Katalog von Maßnahmen. Er sichert die grundsätzliche Entschädigungspflicht des Staates für den Fall, dass in einem Strafverfahren rechtmäßig angeordnete und vollzogene grundrechtsbeeinträchtigende Maßnahmen sich im Nachhinein als nicht erforderlich erweisen oder durch die verhängte Rechtsfolge nicht konsumiert werden ${ }^{165}$. Unerheblich ist, in welchem Stadium des Verfahrens die Maßnahme vollzogen wurde ${ }^{166}$. Anspruchsinhaber ist grundsätzlich jeder, der durch die oben genannten Maßnahmen geschädigt wurde. Voraussetzung ist, dass der Betroffene freigesprochen, das Verfahren gegen ihn eingestellt wurde oder das zuständige Gericht die Eröffnung eines Hauptverfahrens gegen ihn ablehnt.

\subsection{Die einzelnen entschädigungspflichtigen Maßnahmen}

\subsubsection{Die vorläufige Festnahme}

Die vorläufige Festnahme kann nach dem Strafverfahrensrecht von allen Beamten der Polizeidienste vollzogen werden. Entschädigungspflichtig nach § 2 IISatz 2 StrEG ist jedoch nur die vorläufige Festnahme nach § 127 II StPO. Die vorläufige Festnahme nach $\S 127$ I StPO stellt nämlich eine Vorstufe für die Anordnung und den Vollzug einer Untersuchungshaft dar, für

163 D. Meyer, Kommentar zum Gesetz über die Entschädigung für Strafverfolgungsmaßnahmen, Köln 2011, § 2 Rn. 8.

164 K.H. Kunz, Kommentar zum Gesetz über die Entschädigung von Strafoerfolgungsmaßnahmen, München 2010, § 2 Rn. 7.

165 Meyer, Fußnote 163, § 2 Rn. 1.

166 H. Kühne, Strafprozesslehre - Eine Einführung, Heidelberg 1993, Rn. 290. 
die in $\S 2$ I StrEG ein Entschädigungsanspruch bestimmt wird. $\S 127$ II StPO erlaubt der Staatsanwaltschaft und Polizei eine vorläufige Festnahme, ohne dass die Voraussetzungen eines Haftbefehls oder eines Unterbringungsbefehls vorliegen. Voraussetzung ist, dass der jeweilige Amtswalter bei Gefahr im Verzug tätig wird. Dagegen ist die einem Haftbefehl vorangegangene vorläufige Festnahme nach § 127 I StPO nach dem ausdrücklichen Willen des Gesetzgebers nicht entschädigungsfähig ${ }^{167}$.

Die Beschränkung der Entschädigungspflicht auf die Fälle des § 127 II StPO ist nicht unumstritten. Auch eine nach§ 127 I StPO durchgeführte vorläufige Festnahme kann einen erheblichen Vermögensschaden beim Betroffenen verursachen. Weiterhin kann die vorläufige Festnahme nach § 127 I StPO unter Umständen länger dauern als eine solche nach §127 II StPO. Denn gemäß § 128 StPO muss im Rahmen der unverzüglichen Vorführung entweder der Erlass eines Untersuchungshaftbefehls entweder abgelehnt oder erlassen werden ${ }^{168}$. Entsprechend stellt sie ebenfalls einen unmittelbaren und gravierenden Eingriff in sowohl zeitlicher als auch wirtschaftlicher Hinsicht für den Betroffenen dar. Der letztlich überzeugende Grund für die gesetzliche Ungleichbehandlung der Fälle des § 127 I und § 127 II StPO in entschädigungsrechtlicher Hinsicht ist in den deutlich unterschiedlichen Tatbestandsvoraussetzungen der beiden Bestimmungen $\mathrm{zu}$ sehen. Anders als in den Fällen des § 127 I StPO genügt für eine vorläufige Festnahme nach § 127 II StPO nämlich nicht nur ein dringender Tatverdacht, sondern es müssen zusätzlich die Ausnahmevoraussetzungen für den Erlass eines Haftbefehls gegeben sein. Außerdem ist eine vorläufige Festnahme nach $\S 127$ II nur dann zulässig, wenn Gefahr in Verzug gegeben ist. Im Ergebnis entspricht die Festnahme nach § 127 II StPO einer Vorwegnahme des Vollzugs von einer Untersuchungshaft. Dagegen ist die Festnahme nach $\S 127$ I StPO grundsätzlich von vornherein auf eine kurze Dauer angelegt. Aus diesem Grund ist die Wertentscheidung des Gesetzgebers nachvollziehbar, Schäden, die infolge einer Festnahme nach § 127 I StPO entstanden sind, als nicht ersatzfähiges Sonderopfer einzuordnen. Der Betroffene muss die ihm dadurch erwachsenen Vermögensschäden im Interesse der Allgemeinheit selbst tragen ${ }^{169}$.

167 Meyer, Fußnote 163, § 2 Rn. 43.

168 Kunz, Fußnote 164, § 2 Rn. 47.

169 Vgl. Meyer, Fußnote 163, § 2 Rn. 43. 


\subsubsection{Sicherstellung, Beschlagnahme und Durchsuchung}

Ein grundsätzlicher Entschädigungsanspruch kann als Folge einer Sicherstellung, einer Beschlagnahme oder einer Durchsuchung bei dem Beschuldigten entstehen. Die genannten Maßnahmen müssen sich im Rahmen einer Strafverfolgung gegen einen Beschuldigten richten. Es muss also ebenfalls ein konkreter Tatverdacht gegen die Betroffenen gegeben $\operatorname{sein}^{170}$. Die Entschädigungspflicht kann hier ebenfalls nur mit Vollzug der Maßnahme ausgelöst werden. Zum Vollzug der Maßnahme, insbesondere der Dursuchung, gehört auch die Sichtung mitgenommener Unterlagen gemäß § 110 StPO und deren Rückabwicklung ${ }^{171}$.

\subsection{Schaden}

Das Gesetz bezweckt einen materiellen Schadensausgleich des durch den Vollzug der Strafverfolgungsmaßnahme erlittenen Schadens. Daher wird die Entschädigung grundsätzlich nur zum Ausgleich des unmittelbar zuzurechnenden Vermögensschadens gewährt ${ }^{172}$. Die Entscheidung über das Bestehen einer Entschädigungspflicht wird gemäß § 8 StrEG in dem Urteil bzw. Beschluss, der das Verfahren abschließt, ex officio getroffen.

\section{VERHÄLTNIS DER ENTSCHÄDIGUNGSANSPRÜCHE DES STREG ZU ANDEREN ANSPRUCHSGRUNDLAGEN}

Der Gesetzgeber hat ausweislich des Regierungsentwurfs zum StrEG festgeschrieben, dass das StrEG die Haftung des Staates für Eingriffe durch Strafverfolgung nicht abschließend regeln soll ${ }^{173}$. Entsprechend bleiben Amtshaftungsansprüche gemäß Art. 34 GG i.V.m. § 839 BGB von der Regelung des StrEG unberührt ${ }^{174}$. Festzuhalten gilt, dass die Amtshaftungsansprüche in bestimmten Fällen sogar weiter als die Bestimmungen des StrEG gehen und sich auf das Strafermittlungsverfahren als Ganzes beziehen.

So hat der $\mathrm{BGH}^{175}$ eine Amtshaftung auch im Zusammenhang mit

\footnotetext{
170 H.J. Kurth, Identitätsfeststellung, Einrichtung von Kontrollstellen und Gebäudedurchsuchung nach neuem Recht, Neue Juristische Wochenschrift 1979, S. 1382.

171 Kunz, Fußnote 164, § 2, Rn. 54.

172 Meyer, Fußnote 163, Einleitung Rn. 24.

173 Vgl. Bundestags-Drucksache VI/460, S. 7.

174 Meyer, Fußnote 163, Einleitung Rn. 54.

175 BGH, Neue Juristische Wochenschrift 1996, 1128, 1129.
} 
dem Vollzug einer Durchsuchung als Strafverfolgungsmaßnahme angenommen. Die Pflichtverletzung hat sich auf die von der Polizei zu verschuldende Anwesenheit von Medienvertretern bezogen, die von der beabsichtigten Maßnahme durch Indiskretion Kenntnis erlangt haben. Dies gilt besonders dann, wenn dadurch eine öffentliche Vorführung eines Beschuldigten bewirkt wird.

Soweit infolge des Vollzugs einer Strafverfolgungsmaßnahme neben dem Amtshaftungsanspruch ein Entschädigungsanspruch im Sinne des $\S 2$ StrEG entsteht, so ist die Durchsetzung der Ansprüche regelmäßig nach dem StrEG geboten. Andernfalls wäre ein Unterlassen des Beschuldigten als Mitverschulden nach § 254 BGB bei der Geltendmachung von Amtshaftungsansprüchen zu berücksichtigen ${ }^{176}$.

\section{HAFTUNG DES AMTSWALTERS}

\section{KONKURRENZ ZWISCHEN UNMITTELBARER HAFTUNG DES AMTSWALTERS UND DER STAATSHAFTUNG}

Grundsätzlich können mehrere deliktische Ansprüche nebeneinander bestehen, sofern beide auf Ersatz desselben Schadens gerichtet sind. Entsprechend könnte neben der Staatshaftung für unerlaubte Handlung auch eine Haftung des unmittelbaren Schädigers, nämlich des einschlägigen, die hoheitliche Gewalt ausübenden Amtswalters in Betracht kommen. Hierbei könnten die allgemeinen deliktischen Tatbestände eine entsprechende Anspruchskonkurrenz zur allgemeinen Deliktshaftung darstellen.

Sowohl der $\S 823$ BGB als auch der $\S 839$ BGB setzen zur Anspruchsbegründung ein Verschulden des unmittelbaren Schädigers voraus. Beide Rechtsnormen könnten daher in einer Anspruchskonkurrenz zueinander stehen. Damit würde dem Geschädigten ein Wahlrecht bezüglich seiner Anspruchsgegner zustehen, da der Staat und der Beamte die Eigenschaften eines Gesamtschuldners gemäß § 840 I BGB aufweisen würden. Dies führte im Ergebnis zu einer Privilegierung des Geschädigten.

Diese Möglichkeit wird jedoch nach dem ausdrücklichen Willen des Gesetzgebers ausgeschlossen. Die Transformationsnorm des Art. 34 GG bewirkt eine Schuldübernahme der öffentlichen Hand und damit eine Überleitung der Verantwortlichkeit vom Beamten auf den Staat. Es findet

176 Meyer, Fußnote 163, Einleitung, Rn. 54. 
ex lege ein Schuldnerwechsel statt. Im Ergebnis stehen § 823 und § 839 BGB in einer Gesetzeskonkurrenz zueinander. Die Anwendung des § 823 BGB ist damit in Staatshaftungsfällen ausgeschlossen.

\section{REGRESS GEGEN AMTSWALTER}

\subsection{Grundsätzliches}

Hat der Amtswalter durch sein Außenhandeln vorsätzlich oder grob fahrlässig seine internen Dienstpflichten verletzt, kann ihn der Dienstherr in Höhe des Haftungsinteresses in Regress nehmen ${ }^{177}$. Es geht bei der Rückgriffhaftung nicht um den unmittelbaren Schaden der Körperschaft, sondern um den Schaden, der dadurch mittelbar entstanden ist, dass der Dienstherr einem Dritten Schadensersatz leisten musste ${ }^{178}$. Der Regressanspruch des Dienstherrn bemisst sich daher an der Höhe des an den Geschädigten zu zahlenden Betrags.

Aufgrund der im Rahmen der Amtshaftung verfassungsrechtlich angeordneten Schuldübernahmen haftet ausschließlich der Staat unmittelbar gegenüber dem Verletzten. Art. 34 Satz 2 GG benennt jedoch ausdrücklich einen Rückgriffvorbehalt gegen den Amtswalter, sofern den Amtswalter Vorsatz oder grobe Fahrlässigkeit bezüglich der Amtspflichtverletzung trifft. Dieser verfassungsrechtliche Vorbehalt impliziert indessen keine Rückgriffpflicht ${ }^{179}$. Er steckt vielmehr den verfassungsrechtlichenRahmenab, derdurcheinenähereeinfachgesetzliche Regelung ausgefüllt wird ${ }^{180}$ und auch ausgefüllt werden muss ${ }^{181}$.

Die rechtlichen Grundlagen für einen Rückgriff gegen den jeweiligen Amtswalter sind je nach dem Status des handelnden Bediensteten unterschiedlich. Polizeibeamte können als Beamte im statusrechtlichen Sinne nach den insoweit wortgleichen Bestimmungen des $\S 48$ BeamtStG ${ }^{182}$ auf Landesebene (Landespolizeibeamte) und § 75 BBG $^{183}$ auf Bundesebene (Bundespolizeibeamte) zur finanziellen Verantwortung gezogen werden. Das für die Landesbeamten einschlägige Beamtenstatusgesetz findet

177 C. Treffer, Staatshaftung im Polizeirecht, Berlin 1993, S. 119.

178 P. Reinert, [in:] Bamberger, Roth, Fußnote 64, § 839, Rn. 117.

179 Dagtoglou, [in:] BoKo, Fußnote 18, Art. 34 Rn. 348.

180 Ossenbühl, Cornils, Fußnote 4, S. 119.

181 Bonk, Detterbeck, [in:] Sachs, Fußnote 27, Art. 34 Rn. 108.

182 Beamtenstatusgesetz vom 17.06.2008 (BGBl. I S. 1010), das durch Artikel 15 Absatz 16 des Gesetzes vom 5.02.2009 (BGBl. I S. 160) geändert worden ist.

183 Bundesbeamtengesetz vom 5.02.2009 (BGBl. I S. 160), das zuletzt durch Artikel 1 des Gesetzes vom 6.03.2015 (BGBl. I S. 250) geändert worden ist. 
unmittelbare Anwendung und bedarf daher keiner Umsetzung in das jeweilige Landesrecht ${ }^{184}$. Entsprechend sieht etwa das brandenburgische Landesrecht deshalb keine spezialgesetzliche Regelung vor.

Nach dem Wortlaut des $\S 48$ BeamtStG bzw. § 75 BBG haftet der Beamte gegenüber dem Dienstherrn nur bei Vorsatz und grober Fahrlässigkeit ${ }^{185}$. Mit dieser Beschränkung der Rückgriffmöglichkeit soll das „normale“ und „regelmäßige“ Fehlverhalten von Amtsträgern sanktionslos bleiben. Die darin liegende Privilegierung soll die Entschlussfreudigkeit der Beamtenschaft stärken ${ }^{186}$. Weiterhin ist es irrelevant, ob der Beamte den Schaden mittelbar oder unmittelbar verursacht hat und ob er im hoheitlichen oder fiskalischen Bereich gehandelt hat. In all diesen Fällen steht der Anstellungskörperschaft ein Rückgriffrecht $\mathrm{zu}^{187}$. Haben den Schaden mehrere verantwortliche Beamte verursacht, haften sie als Gesamtschuldner.

\subsection{Realisierung des Rückgriffs}

Für die Realisierung des Rückgriffs gegen den handelnden Amtswalter stehen der jeweiligen Körperschaft grundsätzlich verschiedene rechtliche Wege zu. Es kommt zum einen die Aufrechnung gegen Gehalts-, Lohn- und Vergütungsansprüche des Amtswalters in Frage. Weiterhin könnte die Körperschaft einen einschlägigen Verwaltungsakt in Form eines Leistungsbescheids erlassen und diesen unter Umständen im Verwaltungsweg vollstrecken. Zuletzt könnte der Körperschaft ein Klagerecht auf Leistung vor dem zuständigen Gericht zustehen ${ }^{188}$.

Diese zunächst breite Auswahl an Möglichkeiten, den Regressanspruch geltend zu machen, wird jedoch durch den eindeutigen Wortlaut des Art. 34 Satz 3 GG eingegrenzt. Dieser bestimmt, dass der Rückgriff nur mittels einer Klage zum ordentlichen Gericht geltend gemacht werden kann. Diese Vorschrift verwehrt es dem Dienstherrn zugleich $e$ contrario, den Rückgriffanspruch gegenüber dem Amtsträger durcheinen Verwaltungsakt geltend $\mathrm{zu}$ machen und nach dem Verwaltungsvollstreckungsgesetz durchzusetzen ${ }^{189}$.

${ }_{184}$ Das BeamtStG löste zum 1.04.2009 das Beamtenrechtsrahmengestz (BRRG) ab, das einer Umsetzung bedurfte.

185 Diese Rückgriffbeschränkung gilt nicht für Beliehene (BVerwGE 137, 380 ff.) und für als Verwaltungshelfer herangezogene selbständige private Unternehmer (BGHZ 161, 13 f.).

186 U. Battis, Kommentar zum Bundesbeamtengesetz, München 2009, § 78 Rn. 2.

187 Ossenbühl, Cornils, Fußnote 4, S. 120.

188 Ibidem, S. 121.

189 Tremml, Karger, Luber, Fußnote 35, S. 329. 
Umstritten ist jedoch, ob die Aufrechnung einen Verwaltungsakt darstellt. Dies wird teilweise durch die Literatur bejaht ${ }^{190}$. In der höchstrichterlichen Rechtsprechung wird hingegen die Ansicht vertreten, dass die Rechtnatur der Aufrechnung im öffentlichen Recht nicht den Begriff des Verwaltungsakts erfüllt ${ }^{191}$. Damit kann die Aufrechnung neben der Klageerhebung vor den ordentlichen Gerichten der Realisierung des Rückgriffs dienen. In Bezug auf die Regressansprüche gilt die übliche 3-jährige Verjährungsfrist des § 195 BGB. Die Frist beginnt mit Kenntniserlangung des Dienstherrn von dem Schaden und der Person des Ersatzpflichtigen bzw. ab dem Zeitpunkt, in dem der Ersatzanspruch des geschädigten Dritten vom Dienstherrn anerkannt oder ihm gegenüber rechtskräftig festgestellt wurde. Ohne Rücksicht auf Kenntnis des Dienstherrn tritt die Verjährung zehn Jahre nach der Begehung der Handlung ein.

\subsection{Einschränkung des Rückgriffs}

Anzumerken gilt, dass auch bei einem Rückgriff der jeweilige Dienstherr den Grundsatz der allgemeinen Fürsorgepflicht beachten muss. Dieser ist verfassungsrechtlich in Art. 33 GG verankert und gehört zu den hergebrachten und zu beachtenden Grundsätzen des Berufsbeamtentums. Er ist das Korrelat zu dem hergebrachten Grundsatz der Treuepflicht des Beamten ${ }^{192}$. Diese Verpflichtung findet ebenfalls einen Niederschlag in $\S 45$ BeamtStG bzw. 75 BBG. Steht dem Dienstherrn entsprechend eine andere Ersatzmöglichkeit zur Verfügung, so ist aufgrund der Fürsorgepflicht des Staates für seine Beamten ein Anspruch solange ausgeschlossen, bis feststeht, dass die anderweitige Ersatzmöglichkeit nicht durchgesetzt werden kann ${ }^{193}$. Davon abgesehen darf der Rückgriffanspruch nicht so weit durchgesetzt werden, dass der Lebensunterhalt des Beamten gefährdet und der Beamtenberuf unerträglich beeinträchtigt wird ${ }^{194}$. Daher können besondere Umstände des Einzelfalls dazu führen, dass nur teilweise Ersatz gefordert werden kann, ggf. Ratenzahlung bewilligt oder Stundung gewährt wird ${ }^{195}$.

\footnotetext{
190 Vgl. W. Schmidt, Die Aufrechnung mit einer in einem angefochtenen Leistungsbescheid konkretisierten Gegenforderung, Juristische Schulung (JuS) 1984, 29.

191 Vgl. BVerwGE 66, 218.

192 P. Badura, [in:] Maunz, Dürig, Fußnote 6, Art. 33 Rn. 71.

193 Muthers, [in:] Dauner-Lieb, Langen, Fußnote 137, § 839 Rn. 327.

194 Dagtoglou, [in:] BoKo, Fußnote 18, Art. 34 Rn. 350.

195 Bonk, Detterbeck, [in:] Sachs, Fußnote 27, Art. 34 Rn. 108.
} 


\section{RECHTSVERGLEICHENDE SCHLUSSBETRACHTUNG ZUM POLNISCHEN STAATSHAFTUNGSRECHT}

Die Staatshaftung für unerlaubte Handlungen der Polizeibeamten weist in Polen und Deutschland zahlreiche strukturelle Unterschiede auf. Eine besonders herausragende Bedeutung ist den haftungsrechtlichen Kerninstitutionen des Zivilrechts beizumessen. Im Hinblick auf das Verhältnis zwischen der polnischen und der deutschen zivilrechtlichen Anspruchsnorm besteht der zentrale und gleichzeitig folgenreichste Unterschied in der Konstruktion des Staatshaftungsrechts. Der Art. 77 plVerf ${ }^{196}$ i.V.m. Art. 417 plZGB ${ }^{197}$ hat sich im Lauf der Zeit von den Fesseln des subjektiven Haftungsverständnisses gelöst. Dessen rechtsdogmatische Ausgestaltung wird insbesondere vor dem Hintergrund der geschichtlichen Entwicklung nachvollziehbar.

Die in Art. 417 plZGB i.V.m. Art. 77 plVerf niedergelegten Grundsätze der Staatshaftung beanspruchen zwar keine vergleichbar lange Anwendungsdauer wie das deutsche BGB und besitzen keine praxisrelevante Vorgängerregelung im Sinne des Art. 131 Weimarer Reichsverfassung. Zwar sah in der Zweiten Polnischen Republik der Art. 121 der polnischen Verfassung vom 17.3.1921 198 eine staatshaftungsrechtliche Norm vor, diese hatte jedoch keine unmittelbare Anwendbarkeit und es fehlte an einer einfachgesetzlichen Ausgestaltung dieser Verfassungsnorm.

Eine signifikante Änderung dieser Rechtslage vollzog sich erst nach dem Zweiten Weltkrieg im Jahr 1956, als das verabschiedete Beamtenhaftungsgeset $z^{199}$ eine umfassende Staatshaftungsregelung vorsah. Dieses Gesetz wurde anschließend mit dem Inkrafttreten des bis heute geltenden Zivilgesetzbuchs im Jahr 1964 aufgehoben, wobei sein Regelungsgehalt in die Vorschriften der Art. 417-418 des polnischen Zivilgesetzbuchs übernommen wurde ${ }^{200}$. In den darauffolgenden Jahren waren die zivilrechtlichen Staatshaftungsvorschriften Gegenstand der

\footnotetext{
196 Verfassung der Republik Polen [Konstytucja Rzeczypospolitej Polskiej)], Dziennik Ustaw [Gesetzblatt] 1997, Nr. 78, Pos. 483, zuletzt geändert durch Dziennik Ustaw [Gesetzblatt] 2009, Nr. 114, Pos. 946.

197 Polnisches Zivilgesetzbuch [Kodeks Cywilny], Dziennik Ustaw [Gesetzblatt] 1964, Nr. 146, Pos. 93, zuletzt geändert durch Dziennik Ustaw [Gesetzblatt] 2015, Pos. 1844.

198 Verfassung der Republik Polen [Konstytucja Rzeczypospolitej Polskiej], Dziennik Ustaw [Gesetzblatt] 1921, Nr. 44, Pos. 267.

199 Beamtenhaftungsgesetz [Ustawa o odpowiedzialności państwa za szkody wyrządzone przez funkcjonariuszów państwowych], Dziennik Ustaw [Gesetzblatt] Nr. 54, Pos. 243.

200 Z. Banaszczyk, [in:] K. Pietrzykowski, Kodeks cywilny, Komentarz do art. 1-44910 [Zivilgesetzbuch. Kommentar zu Art. 1-44910], Warszawa 2013, Art. 417 Rn. 3
} 
Auslegung durch die höchstrichterliche Rechtsprechung. Im Beschluss vom 15. Februar 1971 stellte das Oberste Gericht zum ersten Mal die sogenannten „Richtlinien für Justiz und Gerichtspraxis hinsichtlich der Haftung der öffentlichen Hand und juristischer Personen des öffentlichen Rechts" 201 auf. Diese galten als verbindliche Auslegungskriterien für die Gerichte und wurden entsprechend bei der Begründung richterlicher Entscheidungen herangezogen. In diesem außerordentlich wichtigen Beschluss hat das Oberste Gericht festgestellt, dass der Art. 417 plZGB eine mittelbare Staatshaftung bestimmt, wonach der Staat verpflichtet ist, jegliche durch seine Amtsträger schuldhaft verursachten Schäden zu ersetzen ${ }^{202}$.

Nach dem Fall des Kommunismus wurde die Verfassungsmäßigkeit der zivilrechtlichen Staatshaftungsvorschriften zunehmend in Frage gestellt. Grund dafür war die Vorschrift des Art. 77 der Verfassung aus dem Jahr 1997. Die nunmehr unmittelbar anwendbare Verfassung garantierte jedem Bürger Anspruch auf Ersatz des Schadens, der durch ein rechtswidriges Handeln der Organe der öffentlichen Gewalt verursacht wurde. Es war zweifelhaft, ob diese Verfassungsvorschrift insbesondere mit Art. 417 plZGB im Einklang stand. Mit dem Urteil des Verfassungsgerichts vom 4. Dezember $2001^{203}$ wurde die bisherige Auslegung des Art. 417 plZGB als mit dem geltenden Verfassungsrecht nicht vereinbar erklärt, allerdings ohne die Vorschrift als verfassungswidrig und damit für nichtig zu erklären.

Das Verfassungsgericht ordnete insoweit eine verfassungskonforme Auslegung der zivilrechtlichen Norm an, wonach die systematische Einstrahlungswirkung des Art. 77 plVerf als lex superior zu berücksichtigen sei. Demnach ist ein Verschulden des Amtsträgers für die Haftungsbegründung entbehrlich und vielmehr das Vorliegen einer rechtswidrigen Handlung ausreichend. Entsprechende klarstellende redaktionelle Änderungen des Wortlauts des Art. 417 plZGB wurden durch den Gesetzgeber im Jahre 2004 vorgenommen. Der geänderte Art. 417 plZGB setzt nunmehr eine „rechtswidrige Handlung oder Unterlassen des Amtswalters während der Ausübung hoheitlicher Tätigkeiten“

\footnotetext{
201 Beschluss des Obersten Gerichts [Uchwała Sądu Najwyższego], III CZP 33/70, Orzecznictwo Sądu Najwyższego - Izba Cywilna/Pracy [Zeitschrift Rechtsprechung des Obersten Gerichts - Zivil- und Arbeitskammer, OSNCP] 1971, Nr. 2, Pos. 59.

202 Vgl. Banaszczyk, [in:] Pietrzykowski, Fußnote 200, Art. 417 Rn. 4.

203 Urteil des Verfassungsgerichts [Wyrok Trybunału Konstytucyjnego], SK 18/00, Orzecznictwo Trybunału Konstytucyjnego; Zbiór Urzędowy [Rechtsprechung des Verfassungsgerichtshofs, Amtliche Sammlung] 2001, Nr. 8, Pos. 256.
} 
voraus. Folglich gilt in Polen für alle einschlägigen haftungsrechtlichen Sachverhalte, die nach dem Inkrafttreten der Verfassung im Jahr 1997 stattfanden, ein verschuldensunabhängiges Haftungsmodell.

Der Verzicht auf das Verschuldenskriterium führte zwangsläufig zu einem Wechsel auf Seiten des Anspruchsgegners. Der Anspruch richtet sich nicht mehr gegen den Amtswalter selbst, sondern gemäß Art. 417 plZGB unmittelbar gegen den Staat, eine Gebietskörperschaft oder eine andere juristische Person, die die öffentliche Gewalt kraft Gesetzes ausübt. Mit der Unmittelbarkeit der Staatshaftung wird die staatliche Leistungsverpflichtung von der Ersatzpflicht des Amtswalters abgekoppelt. Das menschliche Handeln wird durch diese Vorschrift anonymisiert und der öffentlichen Gewalt zugeordnet. Der jeweilige Hoheitsträger (Staat, eine Gebietskörperschaft oder eine andere juristische Person) hat anschließend für das Fehlverhalten einzustehen. Eine Haftungsübernahme, wie sie der Amtshaftungsanspruch gemäß Art. 34 GG i.V.m. § 839 BGB vorsieht, ist aus diesem Grund entbehrlich.

Diese Prinzipien des polnischen Staatshaftungsrechts weisen wesentliche Unterschiede zum deutschen Amtshaftungsanspruch auf. Im Gegensatz dazu stützt sich der deutsche Amtshaftungsanspruch weiterhin auf die personale Konstruktion, die ursprünglich auf die reine Beamtenhaftung rekurrierte. Heutzutage wird zwar aufgrund höchstrichterlicher Rechtsprechung das Verschuldenserfordernis stark modifiziert und "objektiviert". Die durch Art. 34 GG angeordnete Haftungsüberleitung auf den Staat führt jedoch zu dem befremdlichen Ergebnis, dass dem Staat die Haftungsprivilegien zugutekommen, die nach der ursprünglichen ratio legis des $§ 839$ BGB auf den privaten Amtswalter zugeschnitten waren.

Der staatliche Entschädigungsanspruch richtet sich primär auf die Beseitigung des durch die hoheitliche Tätigkeit verursachten Schadens. In einem solchen objektiven Konzept nimmt das subjektive Schulderfordernis eine anachronistische Form an. Meines Erachtens ist ein subjektiv vorwerfbares Verhalten des einzelnen Amtsträgers als Anknüpfungspunkt einer Haftung für hoheitliche Schädigungen nicht zweckmäßig. Streng genommen nimmt der Amtswalter keine persönlichen Pflichten wahr, sondern er realisiert Pflichten des Staates oder einer sonstigen Körperschaft. Er wirkt daher als Hilfsperson mit. Die Amtspflichten haben entsprechend lediglich eine Bedeutung im Innenverhältnis zwischen dem Beamten und seinem Dienstherrn. Im Hinblick auf das Außenverhältnis ist allein 
rechtlich relevant, ob das Verhalten des Staates objektiv rechtswidrig oder rechtmäßig war.

Aus diesem Grund ist die richterliche Rechtsfortbildung des deutschen zivilrechtlichen Amtshaftungsanspruchs zu begrüßen. Die Tendenz zur Objektivierung der Staatshaftung (und damit de facto Aufgabe des Schulderfordernisses) ist darüber hinaus keineswegs auf Deutschland beschränkt. Eine ähnliche Entwicklung hat die polnische Rechtsprechung im Hinblick auf den Art. 471 plZGB vorgenommen und die Rechtsfigur der wina anonimowa (Anonymisierung des Verschuldens) geschaffen. Das heutige Beispiel Polens zeigt zudem, dass das Tatbestandsmerkmal des Verschuldens nicht schlechthin zum Begriff der Staatshaftung gehört. Das richterliche Verständnis und die damit einhergehende Reduktion der Bedeutung des Verschuldensmerkmals für die Staatshaftung kommen der originären - objektiv ausgeprägten - Staatshaftung sehr nahe. Mithin bestehen zwar gravierende konstruktive Unterschiede zwischen der deutschen und polnischen zivilrechtlichen Staatshaftung. In der Rechtspraxis scheitern dagegen nur relativ wenige Staatshaftungsklagen (bzw. Amtshaftungsklagen) an dem subjektiven Tatbestandsmerkmals des Verschuldens ${ }^{204}$.

Ein gewisser tatbestandlicher Unterschied besteht zudem im Hinblick auf das Merkmal der Drittbezogenheit, welches jedenfalls eine funktionale Entsprechung in der Institution der bezprawność względna (relative Rechtswidrigkeit) findet. Beide Merkmale werden in Rechtsprechung und Literatur aufgrund ihrer Bedeutung sehr breit thematisiert ${ }^{205}$. Allerdings ist vor dem Hintergrund des Schwerpunkts dieses Beitrags der etwaigen Divergenz nur eine geringe Bedeutung beizumessen. So ist dieses haftungsbegrenzende Merkmal in polizeirechtlichen Fällen regelmäßig erfüllt, da bei allen polizeirechtlichen Gesetzen durchweg eine individualschützende Qualität angenommen wird.

Unterzieht man die restlichen Erfordernisse der zivilrechtlichen Haftungsnormen einer rechtsvergleichenden Untersuchung, so ergibt sich weitestgehend eine inhaltliche Übereinstimmung der polnischen und deutschen Tatbestandsmerkmale.

Die deutsche Rechtsprechung hat zum einen den Beamtenbegriff von seiner statusrechtlichen Provenienz zu einem funktionalen Beamtenbegriff

\footnotetext{
204 Ausweislich einer Gerichtsaktenauswertung blieben rund 10,4\% aller Klagen aufgrund mangelnden Verschuldens erfolglos; vgl. Bundesministerium der Justiz, Fußnote 159, S. 34.

205 Vgl. dazu etwa in der polnischen Literarur: R. Kasprzyk, Bezprawność względna [Relative Rechtswidrigkeit], Studia Prawnicze [Juristische Studien] 1988, Nr. 3; M. Owczarek, Problem bezprawności względnej w systemie odpowiedzialności deliktowej [Problem der relativen Rechtswidrigkeit im System der Delikthaftung], Palestra [Rechtsanwaltschaft] 2004, Nr. 5-6.
} 
weiterentwickelt. Der unterschiedlich lautende Wortlaut der einschlägigen zivilrechtlichen nationalen Vorschriften ${ }^{206}$ erweckt zunächst den Eindruck, dass dem Merkmal des unmittelbaren Verursachers von Staatsunrecht in Deutschland und Polen verschiedene Bedeutung beigemessen wird. Wie jedoch bereits eingangs vermerkt, erfährt das in § 839 BGB niedergelegte Konzept der Beamteneigenhaftung eine weitreichende Modifikation durch Art. 34 GG. Im Ergebnis wird der zivilrechtliche Beamtenbegriff von einer formellen Amtszugehörigkeit entkoppelt, sodass diese Einstufung dem polnischen, vollständig anonymisierten Begriff des Amtswalters sehr nahe kommt. In beiden Rechtsordnungen zählt allein die Eigenschaft, dass sich eine Person im hoheitsrechtlichen Bereich fehlerhaft verhalten hat. Die statusrechtliche Position eines deutschen Beamten besitzt daher im Ergebnis allein eine das Merkmal des „Haftungsbeamten“ indizierende Funktion. In beiden Rechtsordnungen wird damit letztlich auf das tatsächlich zwischen dem Organ und der geschädigten Person bestehende Rechtsverhältnis abgestellt. Diese teleologische Betrachtungsweise trägt den schutzwürdigen Interessen des Geschädigten Rechnung. Die vom BGH entwickelteLehre „,vonder Nähezumöffentlich-rechtlichenFunktionskreis“ knüpft nahtlos an diese rechtsdogmatische Interpretationsweise an und würde ebenfalls in der polnischen Rechtsordnung aufgrund der axiologischen Vergleichbarkeit des beschriebenen Merkmals keine Widersprüche hervorrufen. Unter Heranziehung des Rechtsgedankens des „Erfüllungsgehilfen “207 ist als Beamter im Sinne des Haftungsrechts jeder anzusehen, der in Erfüllung öffentlich-rechtlicher Pflichten für den Hoheitsträger Dritten gegenüber tätig wird. Daher kann in Deutschland und sollte in Polen auch das Fehlverhalten selbstständiger Werk- oder Dienstunternehmer dem Staat zugerechnet werden.

In beiden Ländern tendiert die Rechtsprechung ebenfalls dazu das Abgrenzungskriterium zwischen privatem und hoheitlichem Verhalten weit auszulegen, obwohl der Art. 34 GG und Art. 417 plZGB einen unterschiedlich lautenden Wortlaut aufweisen. Demnach wird das wertende Zurechnungskriterium „in bzw. bei Ausübung“ durch das funktionale Kriterium der Ausübung des "öffentlichen Amtes" bzw. der „öffentlichen Gewalt“ ergänzt. Zwar wird in der polnischen Rechtsprechung auf eine Unterscheidung zwischen den Begriffen

206 Art. 417 plZGB und § 839 BGB.

207 Dieser Rechtsgedanke ist auch mit dem Prinzip des respondeat superior verwandt, der insoweit auch in den $\S 278$ BGB bzw. Art. 430 und Art. 474 plZGB zumindest im Grundsatz niedergelegt ist. Insbesondere kennt die polnische Rechtsordnung mit Art. 430 plZGB im Gegensatz zum deutschen Deliktsrecht eine generelle Einstandspflicht des Geschäftsherrn, ohne die Erfordernis an dessen eigene Pflichtverletzung anzuknüpfen. 
„äußerer und innerer Zusammenhang“ verzichtet. Gleichsam wird in beiden Rechtsordnungen als Grundlage der Staatshaftung ein adäquater, funktionaler Zusammenhang zwischen dem Schaden und der Handlung verlangt, wobei die Handlung zumindest ein faktischer Ausfluss einer kompetenzrechtlichen Berechtigung sein muss. Sie muss eine hinreichend enge Verbindung zwischen der hoheitlichen Zielsetzung und dem schädigenden Verhalten aufweisen. In beiden Rechtsordnungen wird bei rechtlichen Beurteilungen von Sachverhalten grundsätzlich auf die objektiven Kriterien abgestellt. Das subjektive Kriterium des Zwecks der ausgeübten Tätigkeit besitzt lediglich eine ergänzende Eigenschaft als ungeschriebenes Tatbestandsmerkmal.

Im Rahmen der spezialgesetzlichen Regelungen ist die polizeiliche Unrechtshaftung besonders hervorzuheben. Der in dieser Arbeit erläuterte verschuldensunabhängige Haftungstatbestand nimmt eine wichtige komplementäre Funktion gegenüber der zivilrechtlichen Unrechtshaftung in Deutschland wahr. Im Gegensatz zum Amtshaftungsanspruch haftet der Staat (hier das Land Brandenburg) unmittelbar für sein eigenes Fehlverhalten. Insoweit entspricht die Norm des § 38 BbgOBG der grundsätzlichen Ausgestaltung des Art. 417 plZGB. Anzumerken gilt, dass der auf objektive Kriterien reduzierte Tatbestand des $\S 38$ BbgOBG sehr weit gefasst ist und damit eine einfachere Geltendmachung von Schadenersatzforderungen ermöglicht. Gleichzeitig ist jedoch auf den im Vergleich zur Amtshaftung deutlich beschränkten Haftungsumfang der polizeirechtlichen Unrechtshaftung zu verweisen. Der polizeiliche Ersatzanspruch umfasst nur unmittelbare Vermögensschäden im Eigentum des Geschädigten, sodass etwaige Schmerzensgeldansprüche durch die Norm des Art. 38 BbgOBG nicht gedeckt sind. Aus diesem Grund behält der Art. 839 BGB seine zentrale Bedeutung als staatshaftungsrechtliche Anspruchsnorm. Eine ebenfalls nur komplementäre Bedeutung ist der verschuldensunabhängigen und spezialgesetzlichen Unrechtshaftung für Strafverfolgungsmaßnahmen in Deutschland beizumessen.

Die Rückgriffrechte des Staates gegenüber seinen Polizeibeamten werden in beiden Rechtsordnungen durch vergleichbare Rechtsgrundsätze bestimmt. Entsprechend wird ein Regressanspruch nur dann ausgelöst, wenn dem schädigenden Polizeibeamten ein Verschulden vorwerfbar ist. Hierbei ist in Polen leichte Fahrlässigkeit ausreichend. Der deutsche Gesetzgeber setzt die Schwelle weiter oben an und verlangt mindestens grobe Fahrlässigkeit des Polizeibeamten. Weiterhin bestehen zahlreiche Einschränkungen, die den Regressanspruch gegenüber dem Polizeibeamten 
begrenzen bzw. ausschließen. Diesbezüglich ist besonders auffallend, dass der deutsche Gesetzgeber keine haftungsbeschränkenden Gesetze verabschiedet hat. Die einschlägigen Normen wurden vielmehr durch die ständige Rechtsprechung aus dem verfassungsrechtlich verankerten Fürsorgegebot entwickelt. Im Vergleich dazu hat der polnische Gesetzgeber ein sehr umfassendes Gesetz zur Regelung der Vermögenshaftung von Polizeibeamten erlassen und damit ein hohes Maß an Rechtssicherheit für die Polizeibeamten geschaffen ${ }^{208}$.

Als Ergebnis der Untersuchung der staathaftungsrechtlichen Unrechtshaftung für unerlaubte Handlungen der Polizeibeamten ist auf die herausgearbeiteten konstruktiven Unterschiede eingegangen worden. Hieraus rühren die wesentlichen systematischen Differenzen im polnischen und deutschen Staatshaftungsrecht. Gegenwärtig überlässt es der deutsche Gesetzgeber der Rechtsprechung, das Staatshaftungsrecht im Wege höchstrichterlicher Einzelfallentscheidungen der stetigen Fortentwicklung in der Gesellschaft anzupassen ${ }^{209}$. Die mangelhafte Konstruktion des Amtshaftungsanspruchs wird im Ergebnis mittels einer Vielzahl an komplementären richterlichen und gesetzlichen Tatbeständen behoben. Diese Entwicklung wurde durch eine vornehmlich geschädigtenfreundliche Auslegung der haftungsbegründenden Tatbestandsmerkmale begünstigt, sodass kein akutes Bedürfnis nach einer Neuordnung des Staatshaftungsrechts besteht. Im Gegensatz dazu erfüllt die originäre Staatshaftung des Art. 417 plZGB eine zentrale und grundsätzlich erschöpfende Funktion einer staatshaftungsrechtlichen Anspruchsnorm. Infolgedessen besitzt die polnische Unrechtshaftung für polizeiliche Maßnahmen eine übersichtliche und auch für den Bürger verständliche Systematik.

\footnotetext{
208 Vgl. das Gesetz über die Vermögenshaftung der Polizeibeamten [Ustawa o odpowiedzialności majątkowej funkcjonariuszy policji], Dziennik Ustaw [Gesetzblatt] 1999, Nr. 53, Pos. 548, in der Fassung Dziennik Ustaw [Gesetzblatt] 2015, Pos. 620.

209 Vgl. etwa Kleine Anfrage im Bundestag, 15. Wahlperiode (20.10.2004), BT-Drucksache $15 / 3859$.
} 
